\title{
APORTACIONES A LA EVALUACIÓN DE LOS PROGRAMAS DE DESARROLLO RURAL
}

\author{
Francisco Antonio Navarro Valverde, Eugenio Cejudo García y Juan Carlos Maroto Martos \\ Departamento de Geografía Humana. Universidad de Granada
}

\section{RESUMEN}

Las evaluaciones de los programas de desarrollo rural (PDRs) elaboradas por las diferentes administraciones competentes no tienen suficientemente en consideración los impactos que estos programas generan en el territorio, reduciendo básicamente su análisis a valorar la gestión realizada por los Grupos de Acción Local (GAL). Puesto que consideramos imprescindible avanzar en el conocimiento de las repercusiones socioterritoriales de tales programas, presentamos aquí unas sugerencias, basadas en nuestros trabajos sobre el tema, en las evaluaciones reglamentarias, en las autoevaluaciones de los GAL y en los estudios elaborados desde el ámbito académico, para avanzar hacia la construcción de una más adecuada metodología de evaluación de los PDRs.

Palabras clave: desarrollo rural, evaluación, metodología de evaluación de programas de desarrollo rural, Leader.

\section{ABSTRACT}

The evaluations of the rural development programmes prepared by the various authorities involved have not sufficiently considered the impact that these programmes create in the region, essentially undervaluing the management decisions made by the Local Action Group (LAG). It is vital to increase the knowledge of the socio-territorial impact of such programmes, here we present some ideas, based on our work, regulated evaluations, self-evaluations carried out by the LAG and the papers presented from the academic area, to progress towards a more adequate and practical evaluation of the PDR's.

Keywords: rural development, evaluation, procedures of the evaluation of rural development, Leader.

Fecha de recepción: septiembre 2010.

Fecha de aceptación: febrero 2012. 


\section{PLANTEAMIENTO DEL TEMA/PROBLEMA Y OBJETIVO QUE SE PRETENDE}

Los Programas de Desarrollo rural - LEADER y PRODER en este trabajo-, (en adelante PDRs), llevan aplicándose en los territorios rurales de la Unión Europea (UE) desde hace aproximadamente unos 18 años, teniendo implícitos unos sistemas de seguimiento y evaluación que, por regla general, no tienen en consideración, y si lo hacen de forma muy limitada, la repercusión territorial de las medidas adoptadas, centrándose casi únicamente en el estudio de la aplicación y gestión de tales programas. Y ello a pesar de que los PDRs son de los más evaluados y a los que mayor variedad de métodos de evaluación se les ha aplicado (Esteban et al., 2009: 179). Esto contrasta con la lógica exigencia de justificar todas las inversiones que se realizan, labor que, según manifiestan los encargados de los PDRs que hemos entrevistado, acapara una buena parte de su tiempo de trabajo y de los medios humanos y materiales de los GAL.

La consecuencia de lo anterior es que se obvia uno de los objetivos principales de cualquier evaluación de este tipo, la necesidad de medir adecuadamente las repercusiones de tales inversiones en las condiciones de vida de los habitantes de los territorios rurales donde se aplican. La evaluación del impacto resulta imprescindible, entre otras cuestiones «porque sólo de esta manera es posible observar si los niveles de renta y empleo de las regiones menos desarrolladas se van aproximando a los valores medios de la UE, fin último que persiguen todas las medidas estructurales europeas» (Murillo y Sosvilla-Rivero, 2005: 92). Es decir, debe permitir conocer si tales acciones han contribuido a promover el desarrollo socioeconómico de estos espacios y la reducción de las diferencias de partida respecto a la situación de otras ${ }^{1}$ para lo que «el análisis de las posibilidades reales derivadas de las condiciones sociales, económicas y espaciales de las áreas afectadas» (Alario y Baraja, 2006: 267). Una evaluación global y final adecuada no debe obviar la necesidad de medir si se avanza o no en la consecución de los objetivos que pretendían, así como debe permitir extraer las enseñanzas oportunas de su aplicación, es decir de sus éxitos y fracasos, «si ha tenido éxito o no» (Ray, 2000a: 452) con una visión global y autocrítica. Es en este contexto en el que se justifica la necesidad que tenemos de avanzar en el diseño de métodos adecuados para evaluar estos PDRs.

El objetivo último de esta investigación es aportar unas reflexiones y sugerencias que ayuden a avanzar en el diseño de una más adecuada propuesta metodológica de evaluación de los PDRs. Antes de expresarlas, se hace imprescindible analizar las diferentes formas de entender la evaluación del desarrollo rural que ha propuesto tanto la Comisión Europea, la Unidad Española del Observatorio Europeo Leader, como algunos de los principales especialistas en este tema.

\section{LA EVALUACIÓN POR PARTE DE LOS ORGANISMOS COMPETENTES}

La evaluación de políticas de desarrollo constituye una de las prácticas más complejas y con mayor dificultad de ejecución. Ello no sólo por la diferente forma de entender y abordar

1 Puede ocurrir que la situación de tal espacio no mejore, o incluso empeore, no implicando esto «necesariamente que la ayuda no sea eficiente, sino que la región podría haberse visto empeorada sin la ayuda» (SosvillaRivero et al., 2004: 1). O bien, que los efectos de los PDRs sean contrarrestados por otro tipo de políticas que favorezcan a otras zonas más desarrolladas en mayor medida, como por ejemplo sucede con la PAC, mejor dotada presupuestariamente (Morillas et al., 1999: 225-249). 
la misma ${ }^{2}$ en constante proceso de evaluación y cambio, sino también «por la inexistencia de herramientas apropiadas para desarrollar el seguimiento y control de la programación de inversiones; por la falta de especialistas en la materia y porque no considera rentable evaluar su propia gestión» (Jordá, 1995: 179-181). A pesar de todo ello, cada día se percibe más su necesidad por razones de índole ética, de claridad y finura democrática, y, como no puede ser de otra manera, de eficiencia económica. Puesto que hablamos de fondos públicos, son estos organismos los responsables en primera instancia de realizarlas para dar cumplida cuenta a los ciudadanos de las actuaciones que han subvencionado.

\section{La evaluación desde la Unión Europea}

La reforma y el reforzamiento de los fondos estructurales realizada en 1988 tuvo dos consecuencias importantes: la aparición de una serie de programas de desarrollo rural, y también, «una estructuración en el seguimiento y la evaluación de tales inversiones» (Bachtler y Wren, 2006: 145). La secuencia sintética de los pasos institucionales dados en este sentido se recogen en el cuadro $n^{\circ} 1$.

La iniciativa comunitaria (IC) que se designó para la aplicación de PDRs con enfoque territorial fue LEADER, la cual se comenzó a aplicar a comienzos de la década de los 90. Esta iniciativa ha sido considerada «el último gran escalón en la evolución del desarrollo rural en la UE» (Cazorla-Montero et al., 2005: 707), y «el ejemplo más emblemático de actuación en desarrollo rural» (Cejudo y Maroto, 2010). Para ella se establecen unos objetivos, un método, unas medidas y unas formas de evaluación propias. No en vano, la importancia e interés por su valoración ha llevado a la Comisión a reconsiderar la necesidad de pasar de una evaluación final en LEADER I, periodo 1991-93³; a dos, una intermedia y otra

2 Por poner sólo algún ejemplo, para la iniciativa LEADER, la Comisión $(1997,1)$ estableció los elementos básicos a la hora de evaluarla: situación de partida, objetivos, resultados e impacto. Con la finalidad de mejorar la aplicación del programa dos años más tarde (1999b: 6, 17) incorporó el carácter interpretativo y de juicio de valor que presenta toda evaluación. Por su parte, la Unidad Española del Observatorio Europeo LAEDER (2000: 1) reclamó la necesidad de incorporar aspectos esenciales como su carácter crítico, su independencia y su capacidad de aprendizaje. Por su parte, autores como Viladomiu y Rossel (1988: 297) hacen hincapié en la necesidad de incluir en las evaluaciones las repercusiones que dichos programas tienen sobre el territorio y los cambios que éste experimenta con la aplicación de dichos programas; Delgado y otros (1999: 321) ponen el acento en que el objetivo principal de una evaluación es la determinación de los efectos socioeconómicos que un programa tiene en un territorio en relación a los recursos empleados, Esparcia y Noguera (2000: 79) recalcan la necesidad de una evaluación independiente, objetiva y útil para la toma de decisiones o Santoyo y otros (2002: 15) hacen hincapié en la continuidad, en su visión a largo plazo y en su enfoque sistémico.

3 En esta primera etapa de la IC se identificaron sus elementos característicos, lo que obligó a realizar un esfuerzo metodológico en lo que concierne a su análisis. Se consideraron tres aspectos: la medición de los resultados e impactos de las acciones locales de desarrollo, que se centró en los resultados a nivel local por medidas; la evaluación de la importancia e influencia de los aspectos específicos de LEADER y el análisis del papel de las administraciones nacional/regional y europea en la implementación de la IC. Además de recurrir a la información disponible sobre LEADER, esta evaluación utilizó cuatro instrumentos para recopilar la información adicional necesaria: $1^{\circ}$ una encuesta que recogía información básica del universo de GAL que gestionaban LEADER (217 en total), utilizando material disponible a nivel nacional o europeo y, excepcionalmente, realizando consultas directas; $2^{\circ}$ información cuantitativa y cualitativa en profundidad de una muestra de 50 GAL considerados como representativos del resto; $3^{\circ}$ una serie de entrevistas sobre temas específicos con funcionarios de la UE que estuvieron implicados en la concepción inicial e implementación de LEADER y, $4^{\circ}$, un cuestionario remitido a informantes clave a nivel nacional/regional implicados en la implementación y decisión sobre la financiación de LEADER I. 


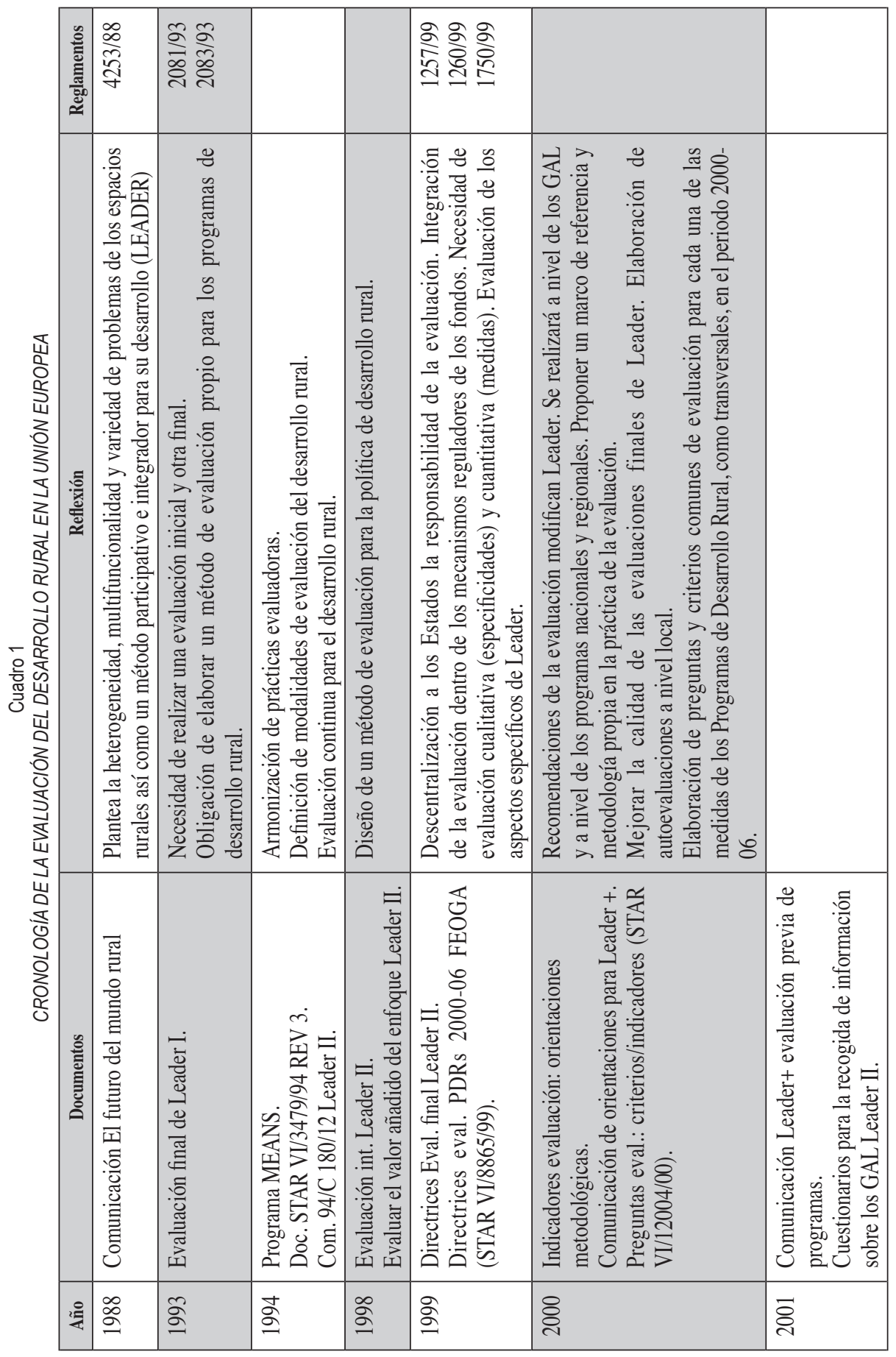




\begin{tabular}{|c|c|c|c|c|c|c|}
\hline 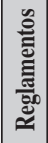 & 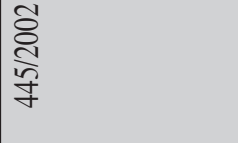 & & $\frac{d}{\frac{5}{\infty}}$ & 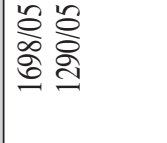 & 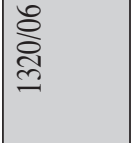 & \\
\hline & 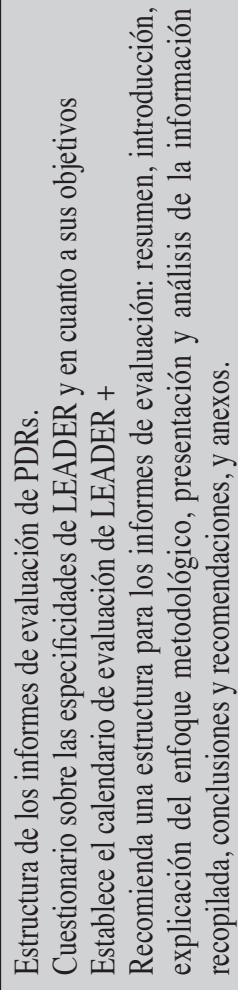 & 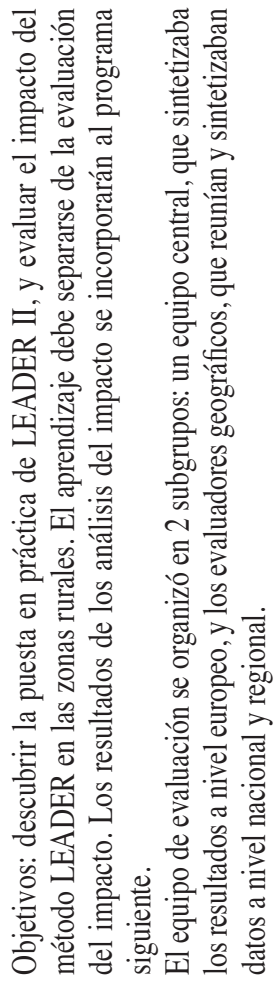 & & 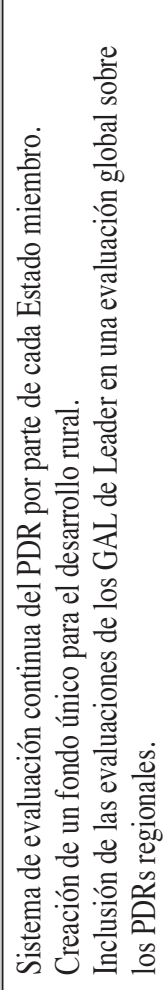 & 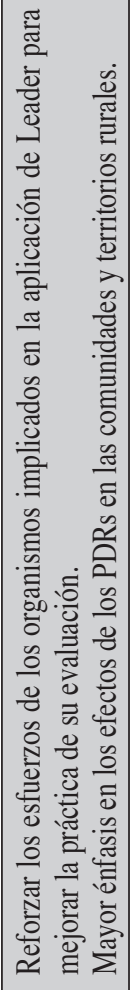 & 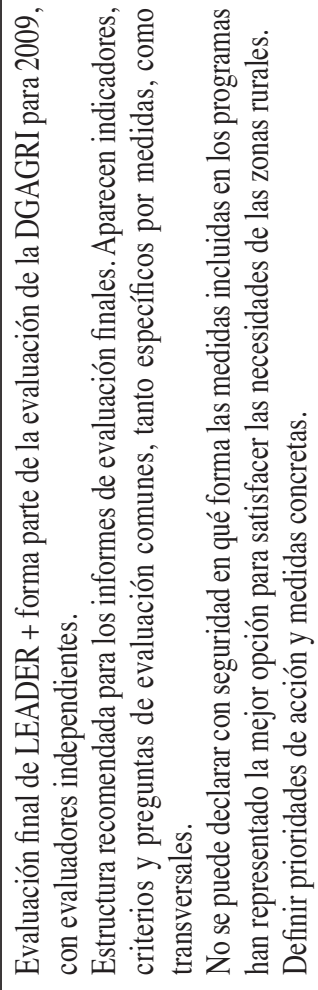 \\
\hline & 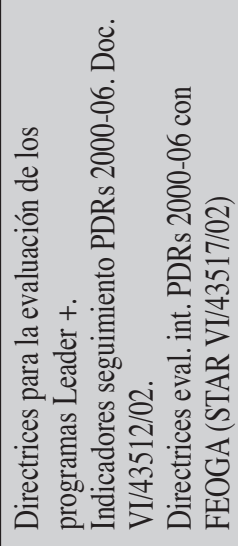 & 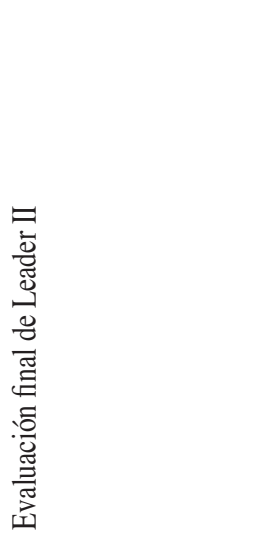 & 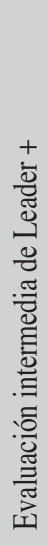 & 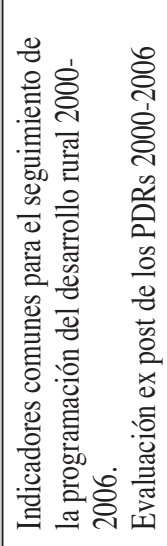 & 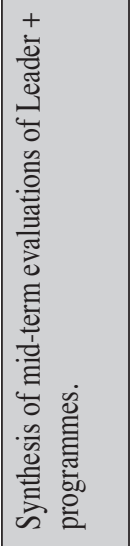 & 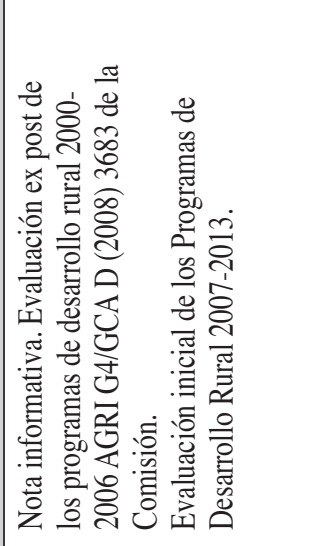 \\
\hline द & ర్ల & ర్ల & ర్తి & ¿્స & శ్రి & ণి \\
\hline
\end{tabular}


final en LEADER II (1995-99); y a tres más recientemente, una inicial, intermedia, y final, en LEADER+ (2000-06).

A pesar de que la evaluación reglamentaria de la iniciativa recogía desde su inicio la necesidad de contemplar tanto aspectos cuantitativos como cualitativos, resultaron evidentes las carencias que existían para que la evaluación de estos últimos obtuviese resultados satisfactorios. Así, los métodos y herramientas que se emplearon durante la evaluación final de LEADER I (Comisión Europea, 1999a) para caracterizar los aspectos específicos del programa fueron diseñados únicamente para centrarse en cuatro temas (acción, partenariado, trabajo en red y financiación), obviando los restantes (innovación, enfoque ascendente, cooperación interterritorial, enfoque territorial, enfoque integrado, multisectorialidad y gestión de proximidad) que singularizan también a los PDRs.

Bachtler y Michie (1995: 748) detectaron en el comienzo de las prácticas evaluadoras de los fondos estructurales (FF.EE.) problemas diversos, unos asociados con las operaciones a realizar, muchos de ellos relacionados con las características propias de la evaluación adoptada y otros con la propia naturaleza de la política comunitaria. En relación a los objetivos, las operaciones de los FF.EE. comprendían una gran multiplicidad de medidas y una escasa cuantía económica; por otro lado, la escala de tiempo no hacía razonable establecer relaciones causa-efecto en las intervenciones de los fondos si no era a medio o largo plazo. A lo anterior se añade que las actuaciones de los FF.EE. eran evaluadas a muy diferentes niveles (proyecto, programa o política), lo que requería acercamientos diversos, difícilmente reconciliables; el hecho de que las acciones eran también implementadas a diferentes escalas espaciales lo complicaba aún más. Para colmo la validez de la información era muy desigual, a nivel microespacial su disponibilidad era insuficiente o nula, por lo que solo se podía realizar una evaluación superficial. Además, debía tenerse presente la polisemia existente en conceptos e indicadores tan importantes como empleo, que no sólo reflejaba falta de coordinación dentro de la UE sino también el uso de métodos de cálculo extremadamente variados, impidiéndose su adecuada comparación. Finalmente, a los anteriores inconvenientes se pueden añadir otros muchos también importantes de entre los que destacamos: la necesidad de determinar qué hubiera pasado en la ausencia de política (efectos contrafactuales), los problemas existentes para calcular efectos indirectos, efectos sinérgicos, la necesidad de establecer qué proyectos o porcentaje de ellos habrían incrementado sus dimensiones gracias a la subvención (adicionalidad), o, por ejemplo, determinar qué proporción de empresas habrían sobrevivido gracias a los fondos.

En consecuencia, las peculiaridades de los PDRs y las circunstancias del momento impedían incluso que su evaluación se adaptara a las técnicas de estudio convencionales basadas casi exclusivamente en análisis de eficiencia, eficacia e impacto. Además estas técnicas se mostraban claramente insuficientes para demostrar la bondad de las iniciativas de desarrollo rural, ya que los objetivos perseguidos dependen también en gran medida de factores intangibles no financieros. Derivado de lo anterior, se hizo necesario mejorar las evaluaciones clásicas que utilizaban casi exclusivamente criterios cuantificables económicamente, para tratar de obtener informaciones adicionales que permitieran medir los impactos cualitativos de estas iniciativas. De este modo, se hizo necesario valorar los aspectos cualitativos y específicos, no sólo para conocer más adecuadamente los resultados de los programas, sino también para exportar sus avances a otros. No olvidemos que junto al carácter experimental e 
innovador que tuvo en su inicio el programa LEADER debe añadirse la exigencia adicional que tenía dicha iniciativa de reivindicarse frente a otras políticas más consolidadas, como la Política Agraria Común (PAC).

Cada vez era más evidente que el éxito o el fracaso de las acciones emprendidas dependían tanto de sus resultados en términos económicos y financieros como de aspectos no tan fácilmente cuantificables, pero muy importantes para la dinámica del desarrollo de una zona rural, como eran el fomento de la participación de los agentes implicados, el debate social o el papel de la innovación en el desarrollo. Así, «para la iniciativa LEADER se generó un debate sobre los métodos más apropiados para su evaluación» (Ray, 2000: 450), discusión que aconteció sobre todo en el seno del Observatorio Europeo LEADER (AEIDL), ante la necesidad de utilizar nuevos instrumentos a la hora de evaluar, capaces de detectar las características específicas de LEADER. Para tratar de establecer una serie de métodos comunes adaptados a los PDRs se confeccionó el documento Evaluar el valor añadido del enfoque LEADER (AEIDL, 1998), que supuso un claro avance en este sentido. En su elaboración participaron tanto expertos en desarrollo rural como las administraciones nacional, regional y comunitaria, que persiguieron principalmente tres objetivos: complementar las orientaciones reglamentarias sobre evaluación realizadas por la Comisión Europea; ayudar a las administraciones y a los GAL a tener en cuenta una serie de consideraciones, las «especificidades», que conferían el «valor añadido» del enfoque LEADER y, por último, diseñar un método de evaluación de la política de desarrollo rural (Saraceno et al., 1999: 5-6). Este documento se convertiría en el punto de referencia fundamental para el diseño de una gran cantidad de iniciativas de evaluación tanto en el seno de los propios GAL como para otro tipo de políticas socioeconómicas europeas, e incluso no europeas, especialmente latinoamericanas.

Sin embargo la metodología cualitativa no se consolidaría hasta la evaluación final de LEADER II en la que, además de abordar las diferentes medidas utilizando indicadores de ese tipo, se trataron las diferentes especificidades de los PDRs. Para la evaluación final de LEADER+ (período de programación 2000-06) la normativa comunitaria establece que su elaboración «forma parte del plan de evaluación de la DG AGRI para el año 2009» (Comisión Europea, 2005: 5). Dicho estudio todavía no se ha concluido, por lo que la utilidad de la evaluación como instrumento de reflexión y aprendizaje ha sido nula en la redacción de los planes estratégicos de los GAL y de los PDRs actualmente en vigor. Por último, hay que señalar que para el período de programación 2007-13, para el que ya se ha realizado la evaluación inicial, la creación de un fondo único para todas las medidas relativas a desarrollo rural (FEADER) ha provocado cambios significativos en la evaluación de los PDRs aplicados por los GAL al incluirse su valoración en una evaluación global de las diferentes medidas de desarrollo rural. Ello es debido a que la metodología LEADER se decide aplicarla a los ejes de los PDRs (Competitividad, Medio ambiente y gestión de la tierra, y Diversificación económica y calidad de vida), convirtiéndose aquél en un eje transversal. Todo ello sin olvidar que además se sigue manteniendo como un eje, el 4, con financiación propia.

\section{La evaluación desde el Estado español}

En España, el análisis y evaluación de los resultados de las políticas públicas cuenta con escasa tradición y menor reflexión teórica. Además «la filosofía tradicional y burocrá- 
tica dominante en la mayoría de las instituciones, en lo que se refiere al diseño y aplicación de políticas, ha supuesto una atención casi exclusiva a los resultados cuantitativos, a las «metas» en cuanto a inversión o número de beneficiarios que una política o programa concreto debía alcanzar» (Noguera y Esparcia, 2000: 104). De hecho, no será hasta que se produzca nuestra entrada en la Comunidad Europea y se hagan efectivas las ayudas de los FF.EE., cuando se haga necesario justificar su utilidad, aplicación correcta y eficacia. Así, para nuestros programas objeto de estudio, «durante los años 1992 y 1993, los programas LEADER fueron objeto de un seguimiento regional, nacional y comunitario, pero no de una evaluación» (Beltrán, 1991: 193-194). LEADER I, como se comentó anteriormente, tan solo contó con una evaluación final ${ }^{4}$.

Hubo que esperar hasta mitad de la década de los noventa para que el Ministerio de Agricultura (1995) estableciese los principios que debían regir nuestras evaluaciones y cuya principal finalidad era conocer en qué medida se habían ido alcanzando los objetivos enunciados por el artículo 130a del Tratado de la UE, tales como la reducción de las diferencias entre los niveles de desarrollo de las distintas regiones y la disminución del retraso de las regiones menos favorecidas y de las zonas rurales. Asistimos también entonces a una clarificación y ordenación de las competencias de evaluación de la iniciativa LEADER entre los distintos niveles de la Administración. Mientras a las Comunidades Autónomas (CC.AA.) se les consideró competentes en la evaluación continua de los distintos proyectos, de las medidas y del conjunto del programa en el ámbito del territorio que gestionan, la Secretaría General de Estructuras Agrarias fue encargada de la evaluación nacional de LEADER, de las evaluaciones temáticas y de los estudios horizontales.

La tarea práctica de la evaluación de los PDRs, tanto LEADER como PRODER, no ha estado exenta de diversas dificultades: la heterogeneidad de fechas de realización, la aplicación de diferentes metodologías en cada Comunidad Autónoma, los retrasos en el desarrollo de los programas, la dificultad para calcular algunos indicadores propuestos, el retraso en su finalización, etc.; circunstancias todas que tuvieron como consecuencia que los Grupos no pudiesen reconducir sus actuaciones en función de los análisis de estas evaluaciones. Para colmo a la demora se añadió la escasa o nula difusión de los resultados al conjunto de los Grupos - muy probablemente ni pretendieron hacerlo - para tratar de evitar suspicacias y roces entre ellos. Lo anterior originó una merma de la necesaria claridad con lo que se propició una injustificable opacidad que es «la antítesis de la evaluación, porque la falta de transparencia es la mejor manera de conseguir lo que se quiere evitar» (Esparcia, 2001: 160).

Las evaluaciones finales de LEADER II y PRODER I realizadas por las diferentes CC.AA. fueron desarrolladas por agentes externos ${ }^{5}$ entre enero de 2000 y abril de 2002 . El

4 Cuyo autor principal fue A. Soy Mar Isla, de la Fundación Bosch Gimpera, de la Universidad de Barcelona.

5 Siendo encargadas a dos tipos de evaluadores. A consultoras, caso por ejemplo de Ecotono para las evaluaciones finales de LEADER II para Asturias, Extremadura y Murcia; Prointec (LEADER II de Aragón, Canarias, Cantabria y Galicia); o de Quasar-Consultores (evaluaciones intermedias periodo 2000-06 de Andalucía, Canarias, Galicia y Murcia), entre otras. O a departamentos universitarios, en la mayor parte de las ocasiones de economía aplicada, como sucede con el Departamento de Economía Aplicada de la Universidad de Valladolid para el LEADER II de Castilla-León, entre otros. La excepción fue Andalucía, donde un centro perteneciente a la Consejería de Agricultura, fue quien realizó la evaluación en el periodo 1995-99; ello introdujo, formalmente al menos, un elemento distorsionador respecto a independencia y objetividad necesarias en los procesos evaluadores, cosa que se subsanó en el siguiente periodo de programación. Además, debe hacerse constar que en las CC.AA. donde la 
estudio del contenido, permite comprobar no sólo que era muy heterogénea la información en la que se basaban las evaluaciones regionales, sino que la estructura utilizada es muy dispar. Se evidencia también una diferente capacidad de medios y de recursos técnicos disponibles, un variado grado de implicación y posicionamiento político, así como diferentes recursos financieros y administrativos de las CC.AA. y de los organismos encargados de la evaluación. Sea como fuere, esta heterogeneidad puso de manifiesto la ausencia de un modelo de evaluación de desarrollo rural, ligado a prioridades operativas, claramente definido. Por lo que al método de evaluación atañe, debe indicarse que al existir ya unas directrices generales de la Comisión, resultó bastante homogéneo en las diferentes CC.AA., recogiéndose indicadores financieros, indicadores cuantitativos de resultados y de impacto, indicadores cualitativos, además de las especificidades de LEADER. Para éstos se abordaron encuestas y entrevistas a beneficiarios, a promotores de proyectos denegados, al gerente y otros miembros del GAL, y a la población local. Terminan los informes con una serie de conclusiones y recomendaciones por GAL. Pero el retraso en la culminación de estas evaluaciones nos lleva a concluir que los informes se quedaron en un simple trámite administrativo, sin apenas finalidades de planificación y de aprendizaje para el diseño de las propuestas del siguiente periodo de programación que se encontraban ya confeccionadas en esas fechas. Además, se obviaron aspectos básicos ligados a la juventud y la igualdad de oportunidades entre hombres y mujeres - cosa que se corrige en 2000-06- Muy discutibles son los datos relativos al empleo y las empresas generadas en la medida en que se recogen los datos aportados por los GAL en sus informes finales cuya veracidad es muy cuestionable. Finalmente, se echa en falta, en la mayoría de los casos, un análisis más profundo y riguroso de las repercusiones del programa en el territorio.

En relación al periodo de programación 2000-06, para cada una de las Comunidades Autónomas, y en cada una de las medidas de desarrollo rural, entre las que se inserta PRODER, se han realizado las evaluaciones finales de los Programas de Desarrollo Rural de las regiones fuera de objetivo 1, pero no de los Programas Operativos Integrados de las regiones objetivo 1, encontrándose únicamente de estas últimas la actualización de la evaluación intermedia. El análisis de las citadas evaluaciones permite comprobar que en sus conclusiones, establecen consideraciones sobre el impacto de tales programas, si es positivo (satisfactorio) o negativo, de grado bajo, medio o alto; establecen las incidencias sobre determinadas variables territoriales: población (despoblamiento, envejecimiento, éxodo rural-inmigración), igualdad (creación de empleo femenino, masculinización), empleo, diversificación, generación de rentas, calidad de vida. Detectamos en ellas múltiples deficiencias, entre las que se podrían destacar: no se estudian los aspectos cualitativos (enfoques ascendente y territorial, innovación, partenariado) en PRODER, ni la repercusión socioeconómica de éstos; salvo excepciones, no se realiza un análisis del reparto territorial y los indicadores que se detallan son excesivamente genéricos (número de acciones, $\mathrm{n}^{\mathrm{o}}$ de proyectos finalizados, etc.), lo que hace que no sean útiles para analizar los progresos alcanzados (ver cuadro $n^{\circ} 2$ ).

evaluación se realizó por una misma consultora, se señalaron conclusiones y recomendaciones similares, por lo que la impresión que produce su análisis es que en ocasiones estos informes se convirtieron en un mero trámite administrativo sin apenas concreción de las características particulares de la aplicación de LEADER en estos territorios. 


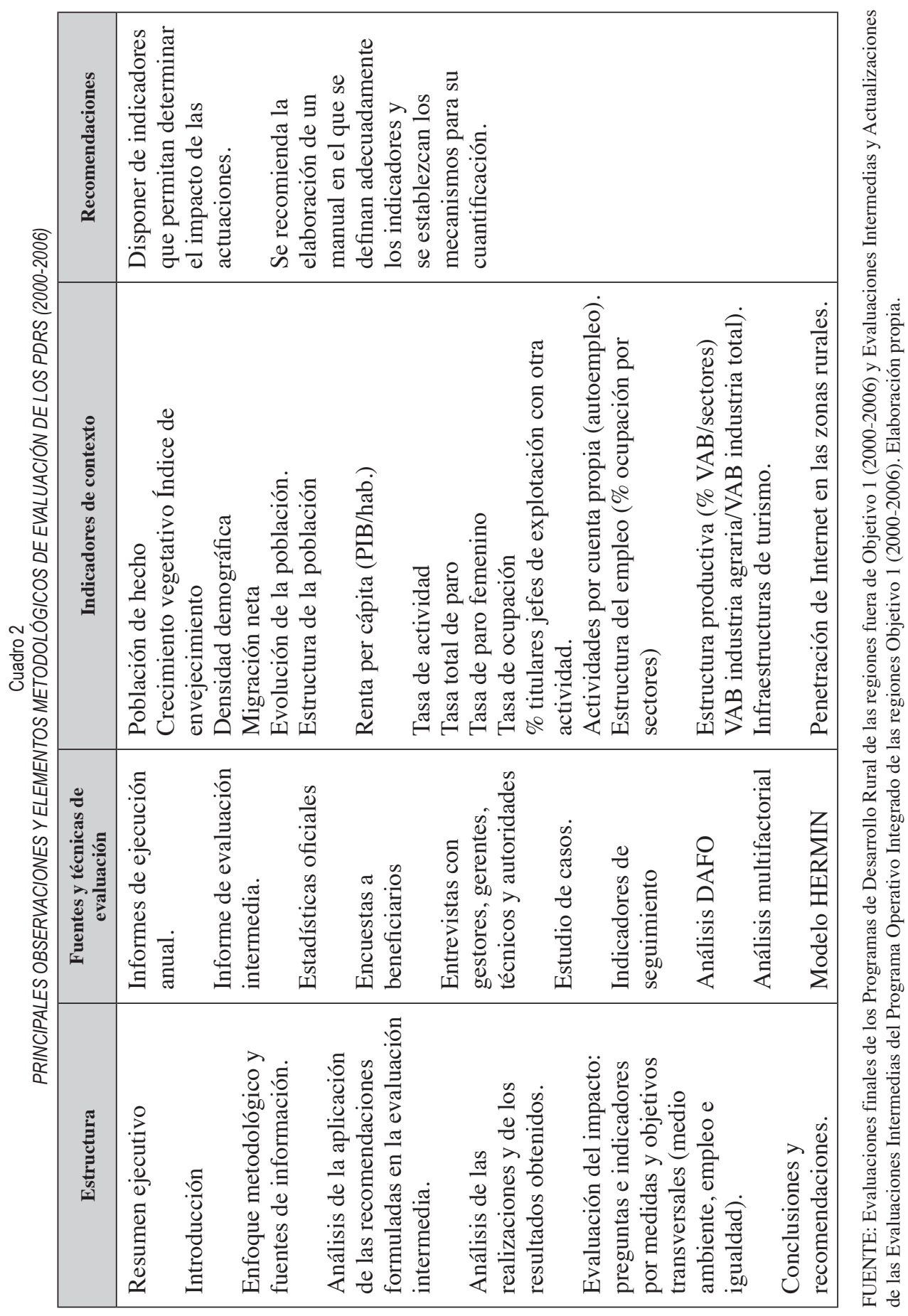


Y, ¿qué ha pasado con LEADER+? Realizadas ya las evaluaciones inicial e intermedia, la final la que «los Estados miembros no están legalmente obligados a realizar» (Comisión Europea, 2005: 5), se inició en enero de 2007 a día de hoy aún no se ha culminado - no se ha podido consultar por no estar acabada en las diferentes CC.AA.- , mientras que ya se ha realizado la evaluación inicial de cada uno de los Programas de Desarrollo Rural regionales del periodo 2007-13 y todos los GAL se encuentran ya desarrollando su nueva estrategia de desarrollo en sus respectivos territorios. Por tanto, las valoraciones que se puedan hacer en base a los datos que aportan las evaluaciones intermedias son poco representativos en la mayor parte de los casos ya que, a pesar de su actualización constante - tal y como se ha podido comprobar en la mayor parte de las CC.AA - , el grueso de los proyectos y de la inversión de este tipo de programas tiende a concentrarse en los últimos meses de la misma, especialmente en algunas medidas, por lo que no es de extrañar porcentajes de ejecución presupuestaria inferiores al $50 \%$ en algunas de estas unos meses antes del cierre del programa. Con estas limitaciones, la evaluación en cada una de las CC.AA. sigue presentando, a nuestro entender, una serie de deficiencias de entre las que cabría destacar: un escaso nivel de detalle, una insuficiente cooperación entre los actores de la evaluación; desconocimiento y subvaloración de su importancia; escasez de recursos de todo tipo para su realización e incluso la no disposición, escasez, deficiente uniformidad e insuficiente informatización de las variables y la información que componen los indicadores de impacto.

Como ya afirmara Noguera (2002: 1), «las políticas y programas de desarrollo se han venido diseñando y gestionando (...) con un proceso de evaluación final con grandes carencias y que no ha permitido conocer su impacto real y sus puntos fuertes y débiles». La mayoría de las evaluaciones elaboradas por las diferentes administraciones siguen limitándose a «facilitar información sobre el grado de ejecución de los proyectos programados o sobre el número de beneficiarios de éstos» (Lima et al., 2010: 109). Existe todavía un largo camino por recorrer en cuanto la evaluación de los PDRs. Los responsables políticos y técnicos tienen que intentar que las evaluaciones posean utilidad, que dejen de ser un puro trámite, una imposición, y pasen a constituir un proceso que permita reflexionar y aprender de las actuaciones emprendidas.

\section{Experiencias de evaluación participativa realizadas por los GAL}

La necesidad de las evaluaciones participativas es cada vez más reconocida en los procesos de planificación y ordenación del territorio; no en vano permiten «conocer la situación del programa en un determinado momento; fomentar el diálogo social a través de la implicación de la población; realizar un seguimiento y control de la información recogida; revisar los objetivos estratégicos del programa o cuantificar los avances obtenidos, comparando los resultados obtenidos en dos momentos temporales distintos» (Delgado et al., 2007: 18-19). Por otra parte, está cada vez más aceptado que en los procesos de valoración de los PDRs se cuente con la participación de la población afectada; e incluso como afirma Ray (2000a: 451) «lo lógico en el desarrollo endógeno es que la evaluación fuera llevada a cabo por las personas que son afectadas por tales iniciativas». En definitiva, la metodología de evaluación participativa, tal y como se refleja en la Comunicación de la Comisión (DOCE C 139/05, 2000: 14), se centra en los aspectos cualitativos del programa, aunque se acompaña también 
de un sistema de valoración de dichos aspectos de carácter cuantitativo, debiéndose llevar a cabo grupalmente o con ayuda de un facilitador. Su adecuada realización requiere la participación de los actores sociales (grupos de interés, técnicos y población en general), por lo que su verdadera utilidad será generar un proceso de reflexión colectiva que conduzca a la creación de referencias comunes entre los agentes del territorio.

Lamentablemente, hay que señalar que los GAL, en términos generales, no han planteado un proceso de evaluación sobre la aplicación de los PDRs en sus respectivos territorios (Seibert 2000). Así, «muchos agentes locales percibieron que la elaboración de los Programas de Innovación Rural era sólo una condición necesaria para acceder a las ayudas. Pocos lo identificaron con una oportunidad para reflexionar sobre el futuro del territorio y las estrategias de desarrollo endógeno más adecuadas y obviamente eso debía implicar la creación de unos mecanismos de participación eficaces. Probablemente una falta de finura democrática, una escasa cultura de participación o un excesivo localismo, son aspectos que contribuyeron a ello» (Esparcia et al., 2000: 102). El excesivo retraso de las evaluaciones reglamentarias, su escasa utilidad e insuficiente nivel de detalle, podían haber propiciado que los GAL hubiesen emprendido un proceso de valoración interna que sirviera para aprender de acciones pasadas, pero quizás hubiera sido pedirles demasiado, envueltos como estaban y siguen estando en una espiral burocrática sin fin.

La consecuencia ha sido que sólo un reducido número de grupos han abordado un proceso de reflexión y probablemente con la única finalidad de preparar el plan estratégico para optar a una nueva iniciativa. Además, no hay que olvidar que estos procesos cuentan con el inconveniente de ser «juez y parte» al mismo tiempo, por lo que parece más que pertinente la necesidad de apoyarse en consultores externos especializados en estos temas (Seibert 2000; Thirion, 2000). Sin lugar a dudas ello favorecería un esfuerzo en la necesaria recopilación de información así como de concreción metodológica que, recogiendo las necesarias percepciones, subjetividades y opiniones particulares de los participantes en la misma, permitan comparaciones y mejoras en el proceso de evaluación. Entendemos que todavía ni los propios GAL ni la sociedad rural están preparados para dirigir la reflexión y la puesta en marcha de las metodologías que exigen los procesos de autoevaluación participativa. A pesar de ello, es imprescindible, por finura democrática y para conocer de una forma más real el impacto de los PDRs, hacerles partícipes del proceso de valoración otorgándoles un papel decisivo, cuestión que casi nunca se hace. No debemos olvidar que, en última instancia, es la población rural la que se beneficia de los éxitos y fracasos obtenidos y por ello cuentan con la legitimidad de incorporar sugerencias para mejorarla. En definitiva, las autoevaluaciones, participativas y próximas al territorio así entendidas, pueden mitigar en parte las deficiencias de las evaluaciones reglamentarias.

\section{Experiencias de evaluación desde el ámbito académico}

El interés por el estudio de la incidencia de los PDRs por parte de investigadores y especialistas en el mundo rural ha sido y es frecuente. Si bien no faltan trabajos desde la sociología, la economía, o incluso la ingeniería agrónoma, han sido más numerosos los llevados a cabo desde la ciencia geográfica presentados tanto en distintas reuniones científicas periódicas (coloquios bienales de la Asociación de Geógrafos Españoles, coloquios del grupo 


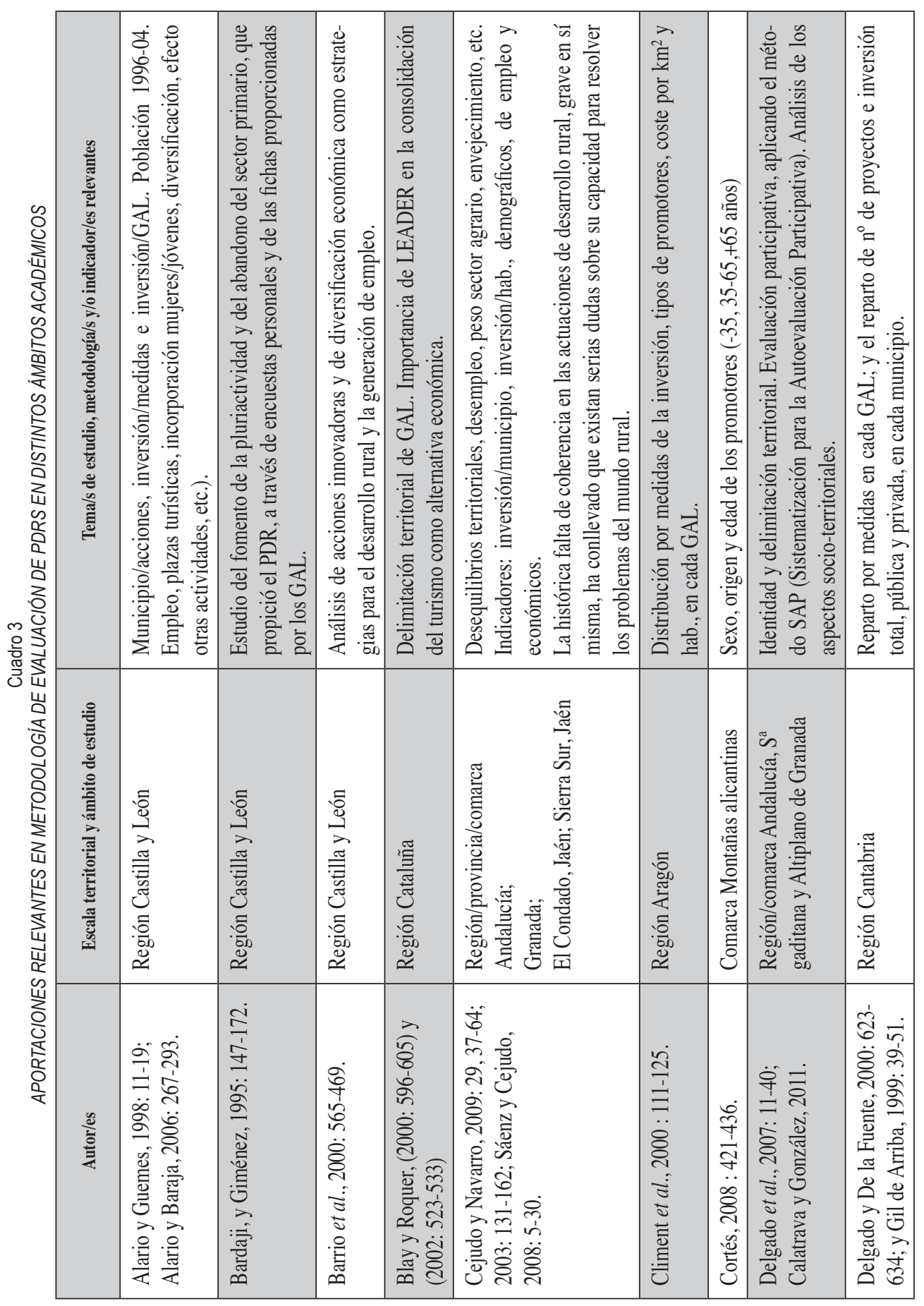




\begin{tabular}{|c|c|c|c|c|c|c|c|c|c|c|c|c|}
\hline 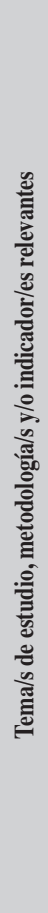 & 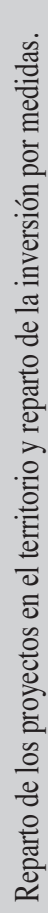 & 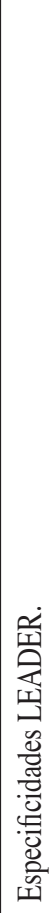 & 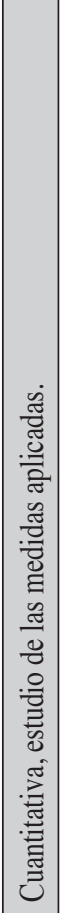 & 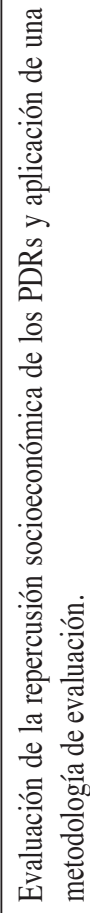 & 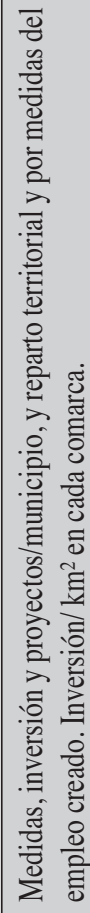 & 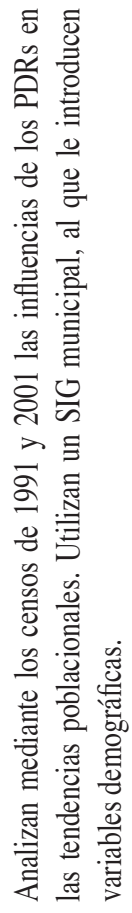 & 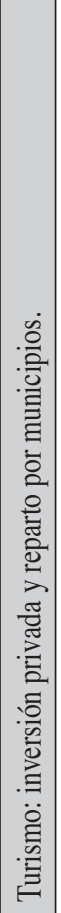 & 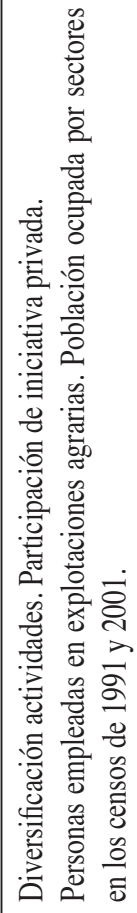 & 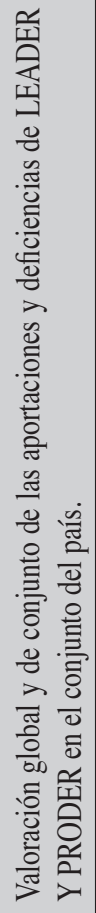 & 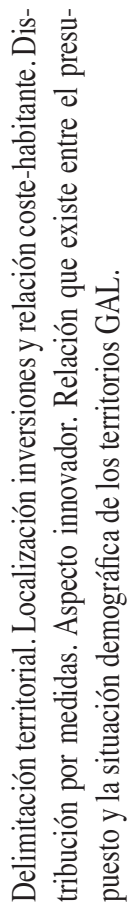 & 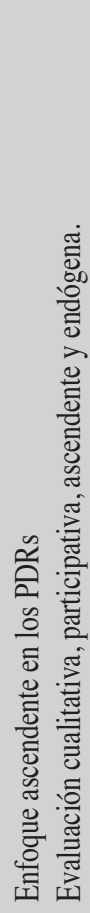 & 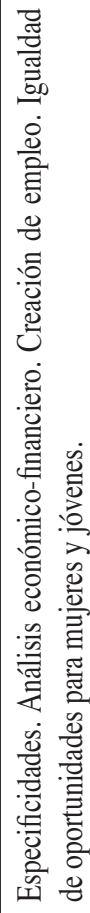 \\
\hline 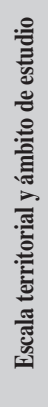 & 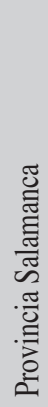 & 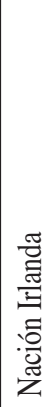 & 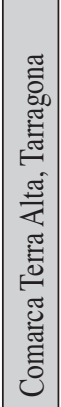 & 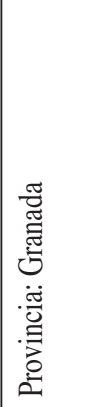 & 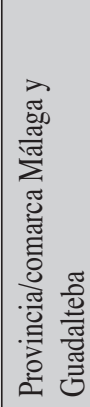 & 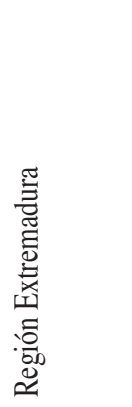 & 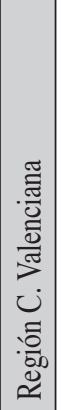 & 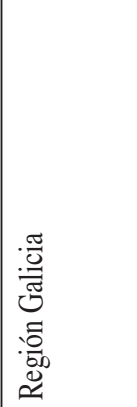 & 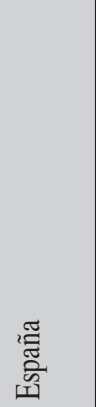 & 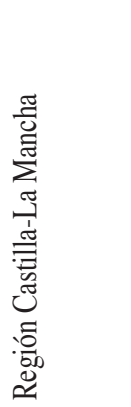 & 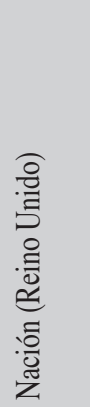 & 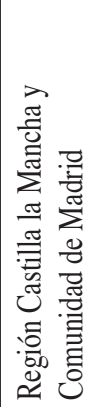 \\
\hline 亲 & 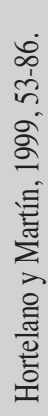 & 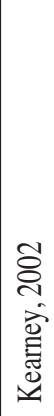 & 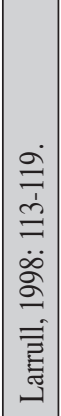 & 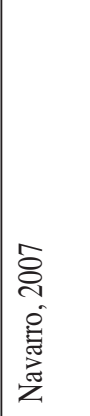 & 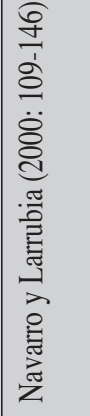 & 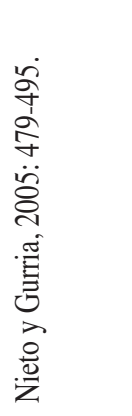 & 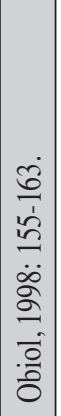 & 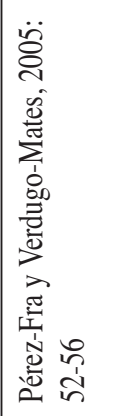 & 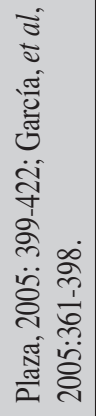 & 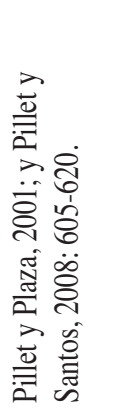 & 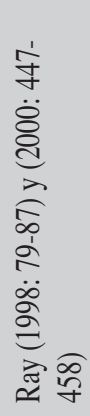 & 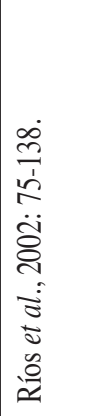 \\
\hline
\end{tabular}




\begin{tabular}{|c|c|c|c|c|c|c|}
\hline 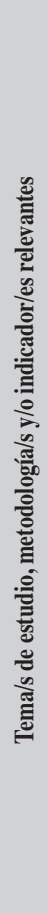 & 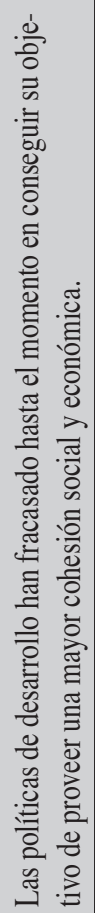 & 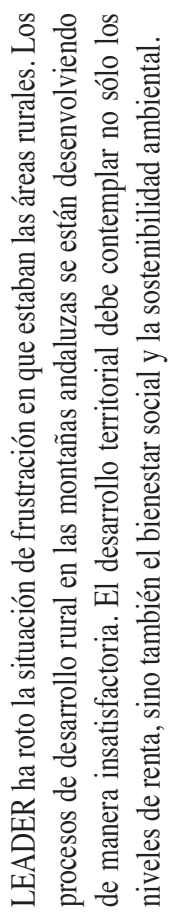 & 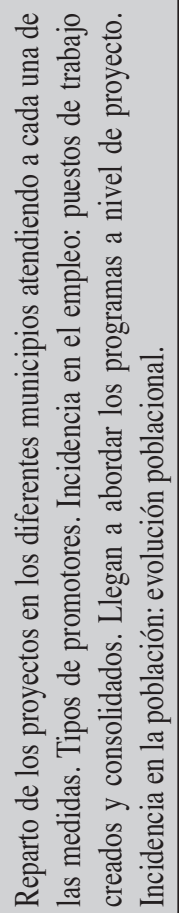 & 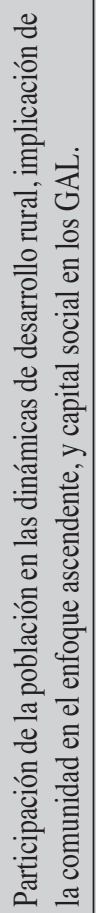 & 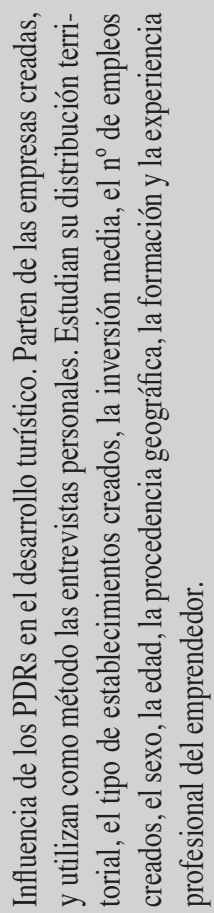 & 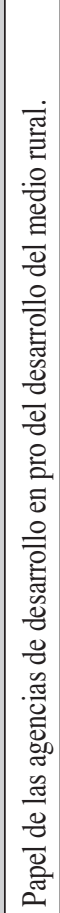 \\
\hline 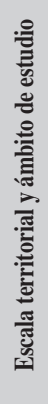 & 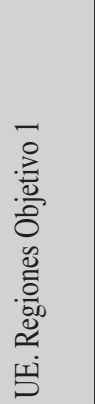 & 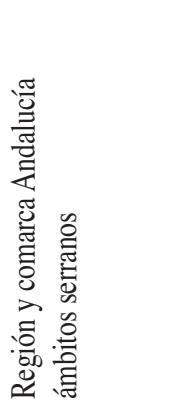 & 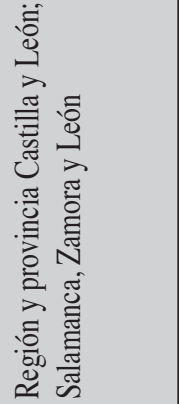 & 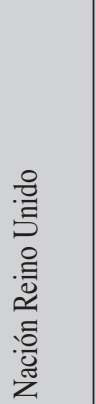 & 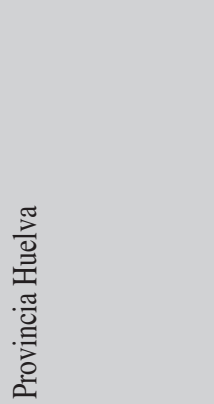 & 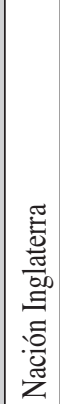 \\
\hline 王 & 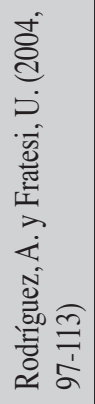 & 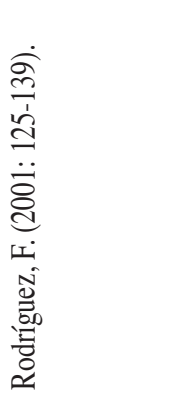 & 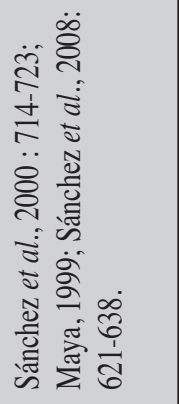 & 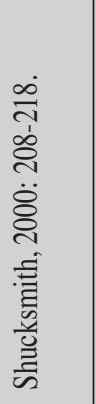 & 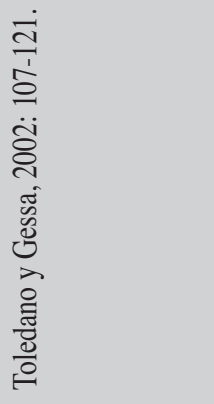 & 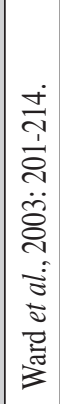 \\
\hline
\end{tabular}


de trabajo de Geografía Rural) y no periódicas, como en los trabajos publicados en diferentes revistas. Las «evaluaciones», «estudios», «análisis» y «valoraciones» de los PDRs realizadas desde el ámbito académico, en líneas generales, se caracterizan por realizar una descripción geográfica inicial, un estudio de las medidas ejecutadas en cada una de las comarcas, provincias o regiones, un análisis de su montante económico, una valoración de sus especificidades y en algunas ocasiones también un examen de la distribución territorial. Llama la atención que frecuentemente el análisis crítico es muy escaso cuando se aborda su incidencia territorial y social. Como afirman Márquez et al. (2005: 138) «las políticas de desarrollo rural en las áreas LEADER y PRODER han tenido resultados y efectos desiguales, hecho que ha sido percibido pero no suficientemente evaluado». Algunos estudios que han realizado aportaciones significativas se recogen en el cuadro $\mathrm{n}^{\mathrm{o}} 3$.

\section{CONSIDERACIONES PARA EL ANÁLISIS DE LA REPERCUSIÓN TERRITORIAL DE LOS PDRS}

En nuestra propuesta, sustentada en un importante número de trabajos realizados hasta la fecha ${ }^{6}$, se intenta dar un paso más, procurando no solo evaluar el programa en sí, sus objetivos, especificidades y medidas, sino también su repercusión en el territorio, añadiendo a las cuestiones anteriores, una serie de interrogantes, herramientas, indicadores, planteamientos, y experiencias que permitan aproximarnos todo lo posible a la repercusión real de tales programas tratando de solventar algunas de las carencias de las evaluaciones analizadas anteriormente.

El éxito del planteamiento, del método y del enfoque LEADER es incuestionable, lo corrobora que «su filosofía ha sido adoptada en iniciativas similares, adaptadas a sus contextos específicos, aplicadas en otros países -nuevos Estados miembros de la UE, otros países de la OCDE, y de América Latina-» (Arkleton Institute, 2004: 182), en otras medidas de desarrollo rural, en otras ICs - INTERREG III e EQUAL - e incluso en otras políticas sectoriales y territoriales, tanto de la UE como de sus países miembros. Sin embargo cuando se aborda un estudio particularizado, a escala regional o local, teniendo en cuenta los objetivos que se pretendían alcanzar y las situaciones de partida, su éxito ya no resulta tan claro. Como señalan Guzmán et al. (2001: 5) «para la evaluación del territorio, se deben analizar sus características y su evolución a lo largo del programa, haciendo un especial hincapié en los criterios que definen el área de actuación, su identidad cultural y la disponibilidad de recursos para propiciar un proceso de desarrollo». Además hay que tener presente que los territorios tienen múltiples singularidades y que la diversidad de los espacios rurales es un hecho que conviene tener presente para evaluar correctamente la implantación absoluta y relativa de las políticas de desarrollo rural en la corrección de los desequilibrios territoriales y las desigualdades socioeconómicas. En consecuencia, la componente territorial, con sus diferentes particularidades, es un elemento esencial a tener en cuenta a la hora de evaluar correctamente un programa de desarrollo rural.

Respecto a la escala espacial de análisis, se opta por la municipal, cuando la información a representar así lo demanda, siendo la más adecuada para apreciar las incidencias de los

6 Como más relevantes, Tesis doctorales (Navarro, 2007), publicaciones en revistas (Cejudo y Navarro; 2009: 37-64; 2003: 131-162), entre otras. 
PDRs, o comarcal, cuando se pretende ofrecer una visión de conjunto o comparativa con las actuaciones de diferentes GAL en otros territorios de actuación. En cuanto a la escala temporal, consideramos que es conveniente abordar los tres periodos de programación ya culminados por parte de la UE: 1991-93 (LEADER I); 1995-99 (LEADER II y PRODER I); y 2000-2006 (LEADER + y PRODER II). Una referencia temporal que en el conjunto de sus 15 años permite apreciar algunos de los impactos de la aplicación de tales programas en los territorios que se analicen.

Consideramos que para realizar una buena evaluación es necesario compaginar la utilización de información cuantitativa y cualitativa con carácter normalizado y complementario. Respecto al primer tipo de información se puede trabajar con los datos ofrecidos por la estadística oficial disponible aunque de manera limitada, no sólo por la inexistencia de series históricas para analizar la tendencia no facilita la aplicación de técnicas de análisis adecuadas sino porque se hace preciso seguir avanzando para disponer de información a escala municipal común para toda la UE. También es obligado, y previo para tratar de hacer una adecuada evaluación, consultar la documentación construida por los GAL en sus informes anuales y finales. Ahora bien, a causa de que la documentación normalmente disponible es en muchas ocasiones sesgada, incompleta y que no abunda en determinadas cuestiones de tipo cualitativo que entendemos fundamentales, se considera imprescindible el trabajo de campo que permita recabar información de cada uno de los emprendedores beneficiados por los $\mathrm{PDRs}^{7}$. Lo anterior debería completarse con otro cuestionario dirigido a los gerentes de los GAL, ya que consideramos que éstos nos pueden dar las claves de las especificidades y de los objetivos de LEADER. Las ventajas del empleo de las entrevistas en este proceso ya fue avalado por la Comisión Europea al señalar que «suministran información en profundidad y valoraciones, hechos y comportamientos de los entrevistados, y los efectos que en ellos han causado los programas» (1999c: 67).

De manera sintética nuestras sugerencias para tratar de llegar algún día a una necesaria, normalizada y operativa metodología de evaluación de los PDRs se basan, como hemos resumido en el cuadro $\mathrm{n}^{\circ} 4$, en diversas cuestiones que consideramos esenciales.

Derivado de nuestra experiencia proponemos, un cuestionario, cuadro $\mathrm{n}^{\circ} 5$, para recabar información a los emprendedores beneficiados de las subvenciones que permite realizar un acercamiento al impacto real de los PDRs. Aunque la mayoría de las preguntas son cerradas, consideramos aconsejable para futuros estudios dar un margen mayor de libertad a las respuestas del entrevistado y reducir en lo posible la excesiva simplificación que todo cuestionario origina. Los objetivos que persigue es conocer una serie de características sociodemográficas del emprendedor, de la empresa, del proyecto, de los trabajadores, innovación y por último, la opinión personal y valorativa de los PDRs y de los territorios Leader-proder.

7 Se descartan las entrevistas a promotores públicos al ser sus inversiones «no productivas», incluyendo en la lista: la gran variedad existente en la tipología de empresas; que los encuestados formen parte de las tres medidas productivas (turismo rural, pymes, artesanía y servicios locales, y valorización de la producción agraria, ganadera y forestal); proporcionalidad por sexos; y por último, que sean de diferentes GAL, de distintos periodos de programación y diferentes municipios, siendo representativos de cada uno de ellos. Además, en las empresas en las que sean varios los emprendedores asociados se decide entrevistar al más implicado en el proyecto empresarial llevado a cabo gracias a los PDRs. Por último, el $n^{\circ}$ de entrevistas tiene que ser representativo del universo total de emprendedores beneficiados. 


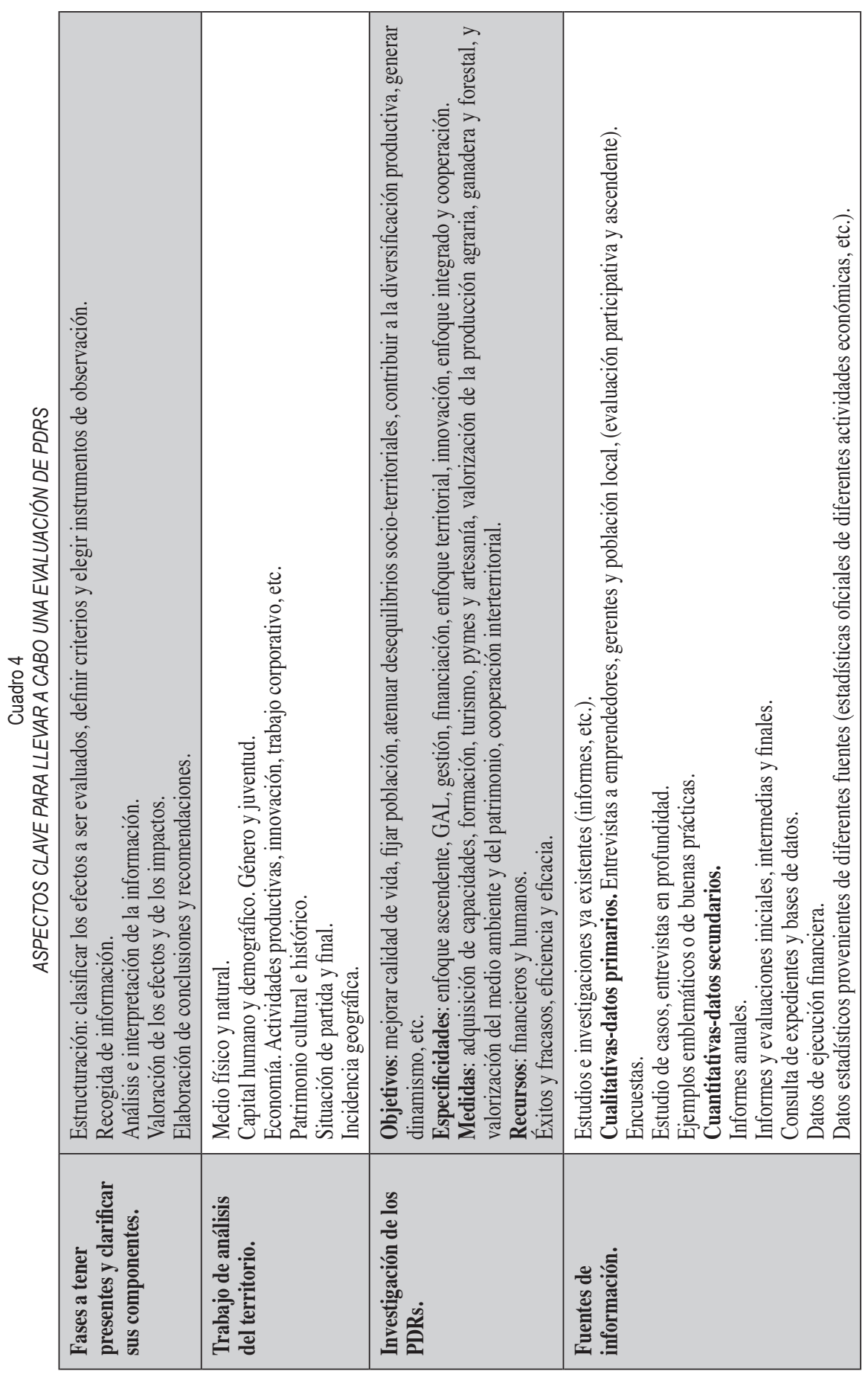




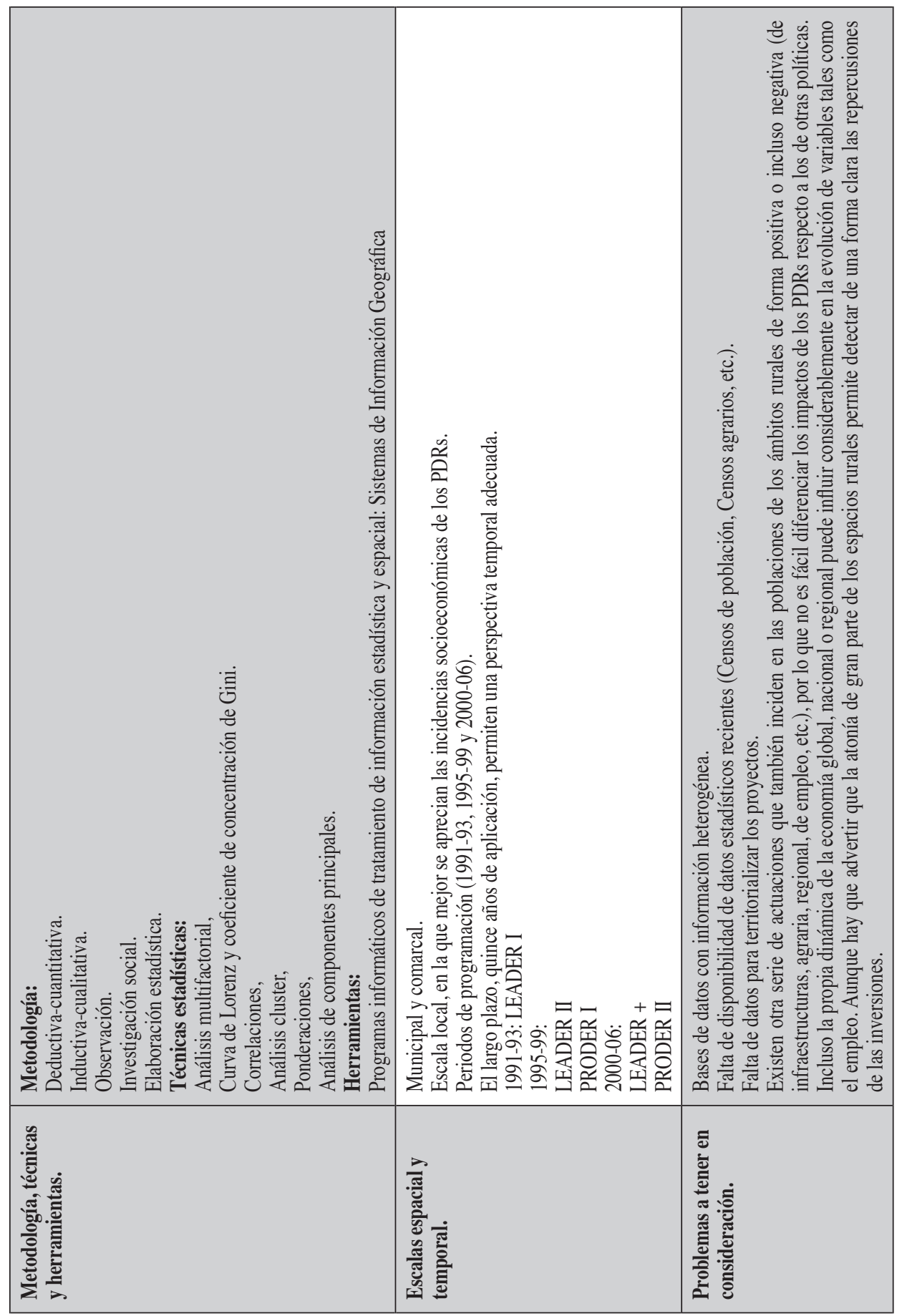

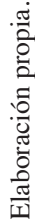




\section{En cuanto al emprendedor:}

Sexo: Hombre o Mujer

Edad: 20-25, 25-30, 30-35, 35-40, 40-45, 45-50, 50-55, 55-60, 60-65, +65

Nivel de estudios del emprendedor: sin estudios, primarios no acabados, primarios ó E.G.B., Bachillerato, C.O.U., Formación Profesional, otro tipo de estudios secundarios, universitarios o superiores.

Formación en el ramo: sí o no.

Experiencia emprendedor y profesión anterior.

Agricultor que diversifica actividad: sí o no.

Procedencia territorial: propio municipio, otro municipio de la zona Leader-Proder, otra comarca, otra provincia, otra comunidad autónoma y otro estado.

\section{En cuanto a la empresa:}

Tipo de empresa: Asociación, Autónomo/a, Ayuntamiento, C.B., Cámara de Comercio, Club deportivo, Comunidad de Regantes, Comunidad de Vecinos, Consorcio, Diputación, Entidad Local, Entidades Financieras, Grupo Desarrollo Rural, Grupo empresarial, Iglesia, Mancomunidad, Patronato, S.A., S.A.L., S.A.T., S.C.A., S.C.L., S.C.P., S.L., S.L.L., Sociedad o Universidad.

Causas elección tipo de empresa.

Tamaño de la empresa: individual, microempresa (menos de diez trabajadores), pequeña empresa (de 10 a 50 trabajadores), mediana $(50-250)$, y grande $(+250)$.

Volumen de ventas anuales: menos de 6.000 euros, 6.000-30.000, 30.000-60.000, 60.000-300.000, 300.000-600.000, 600.000-3.000.000, mas de 3.000.000.

Radio territorial de venta del producto o servicio: internacional, nacional, regional, subrregional, provincial, comarcal o local.

\section{En cuanto al proyecto beneficiado de la ayuda:}

\section{Fecha realización:}

Crea, amplía o moderniza empresa: crea, amplía o moderniza.

¿En qué medida las ayudas europeas han permitido la creación o consolidación de la empresa?: ninguna, poco, algo, bastante ó muchísimo.

Procedencia del capital propio invertido.

En cuanto a los trabajadores:

Edad media empleos nuevos: 20-25, 25-30, 30-35, 35-40, 40-45, 45-50, 50-55, 55-60, $60-65,+65$

Nivel de estudios trabajadores nuevos: sin estudios, primarios no acabados, primarios ó E.G.B., Bachillerato, C.O.U., Formación Profesional, otro tipo de estudios secundarios, universitarios o superiores.

Profesión anterior trabajadores nuevos.

Edad media empleos consolidados: 20-25, 25-30, 30-35, 35-40, 40-45, 45-50, 50-55, $55-60,60-65,+65$. 


\section{Procedencia sectorial trabajadores. \\ Procedencia territorial trabajadores: propio municipio, otro municipio de la de la zona Leader-Proder, otra comarca, otra provincia, otra comunidad autónoma y otro estado. Relación laboral con el empresario: contratados, ayuda familiar, autónomos, otros tipos.}

\section{En cuanto a la innovación:}

Tipo de innovación: maquinaria, herramientas o tecnología nueva; nuevo producto o servicio complementario; abrir el negocio a nuevas actividades; búsqueda de nuevos mercados; mejores respuestas a problemas de la empresa.

Empleo de nuevas tecnologías: sí o no.

Uso de Internet: sí o no.

Opinión personal y valorativa sobre los programas de desarrollo rural y sobre la de la zona Leader-Proder:

Razones para emprender: por falta de ofertas de empleo, experiencia en el sector, cubrir necesidades no satisfechas, creación de un producto o servicio nuevo.

Conocimiento ayudas.

Opinión sobre los programas de desarrollo rural: excelente, buena, indiferente, regular, y mala.

Obstáculos encontrados en los programas de desarrollo rural: excesiva burocracia, demasiado tiempo desde petición ayuda hasta recepción fondos, excesiva especificidad de las ayudas, limitación de los fondos destinados a ayudas, desconocimiento de la existencia de ayudas o falta de información.

Hubiera invertido sin ayuda: sí o no.

Perspectiva de futuro que le ve a la de la zona Leader-Proder: excelente, buena, regular ó mala.

Perspectiva de futuro que aprecia en el sector o actividad: excelente, buena, regular ó mala.

Le gustaría que su hijo siguiera en la actividad y en la de la zona Leader-Proder: sí o no.

\section{A rellenar por el encuestador:}

Actitud del emprendedor ante la entrevista: excelente, buena, regular, reticente, muy reticente, o al límite de abandonar.

Otras observaciones.

Elaboración propia.

Este cuestionario nos proporciona, por una parte, una gran cantidad de información cualitativa, que no aparecen en otra serie fuentes, ni en los informes finales de los GALs, ni en las estadísticas oficiales, y por otra parte, un conocimiento más actualizado sobre los impactos intangibles. 
Cuadro 6

ASPECTOS E INTERROGANTES A CONSIDERAR EN UNA EVALUACIÓN DE UN PDR

\begin{tabular}{|c|c|}
\hline Aspectos y objetivos a considerar & Interrogantes e indicadores (cualitativos y cuantitativos) \\
\hline Enfoque ascendente & $\begin{array}{l}\text { Acciones emprendidas para asegurar la participación en las ayu- } \\
\text { das y PDRs. } \\
\text { Grupos sociales que participan con mayor intensidad en las ayu- } \\
\text { das y PDRs. }\end{array}$ \\
\hline GAL, financiación & Origen, proceso de formación, componentes y objetivos. \\
\hline Gestión & $\begin{array}{l}\text { Grado de autonomía del GAL y apoyo de la Admón. } \\
\text { Beneficiarios: conocimiento de las ayudas, opinión de los PDRs } \\
\text { y obstáculos encontrados. }\end{array}$ \\
\hline Financiación & $\begin{array}{l}\text { Facilidad en el acceso a los fondos, retraso en el pago de las } \\
\text { ayudas y decisiones financieras innovadoras. } \\
\text { Medida en que las ayudas han permitido la creación o consoli- } \\
\text { dación de la empresa. } \\
\text { Procedencia del capital propio invertido. }\end{array}$ \\
\hline Delimitación territorial & $\begin{array}{l}\text { Otras delimitaciones existentes, proceso de conformación espa- } \\
\text { cial e identidad territorial. Ventajas de la delimitación propuesta } \\
\text { respecto a otras posibles. }\end{array}$ \\
\hline Recursos endógenos & $\begin{array}{l}\text { Análisis de la medida de valorización del patrimonio ambiental } \\
\text { y cultural (cuantía, distribución territorial e incidencia en recur- } \\
\text { sos locales). }\end{array}$ \\
\hline $\begin{array}{l}\text { Reducción de las desigualdades } \\
\text { territoriales }\end{array}$ & $\begin{array}{l}\text { Reparto municipal de la inversión total, pública y privada. } \\
\text { Relación del reparto de la ayuda con la renta per cápita u otros } \\
\text { indicadores de dinamismo económico. }\end{array}$ \\
\hline $\begin{array}{l}\text { Población (éxodo rural y } \\
\text { envejecimiento)* }\end{array}$ & $\begin{array}{l}\text { Situación de determinadas variables demográficas (evolución, } \\
\text { natalidad, mortalidad, crecimiento vegetativo, movimientos mi- } \\
\text { gratorios, crecimiento real y estructura por sexo y edad, entre } \\
\text { otros) en los momentos inicial y final de la aplicación del PDR. }\end{array}$ \\
\hline Juventud & $\begin{array}{l}\text { Edad de los emprendedores y los trabajadores, nivel de estudio } \\
\text { y formación en la actividad, modalidad de la inversión, tamaño } \\
\text { empresarial y volumen de ventas. }\end{array}$ \\
\hline Igualdad de oportunidades & $\begin{array}{l}\text { Peso de las emprendedoras y trabajadoras (por medidas, edad, } \\
\text { educación, experiencia profesional, tipo inversión, tamaño em- } \\
\text { presarial, volumen de ventas) en comparación con el sexo mas- } \\
\text { culino. }\end{array}$ \\
\hline Formación & $\begin{array}{l}\text { Nivel formativo y cualificación profesional de los empresarios } \\
\mathrm{y} \text { trabajadores } \\
\text { Análisis de la medida de formación (acciones, sectores, grado } \\
\text { de inserción laboral, } \mathrm{n}^{\circ} \text { personas formadas, etc.). }\end{array}$ \\
\hline
\end{tabular}




\begin{tabular}{|l|l|}
\hline \multicolumn{1}{|c|}{ Aspectos y objetivos a considerar } & \multicolumn{1}{|c|}{ Interrogantes e indicadores (cualitativos y cuantitativos) } \\
\hline Empleo & $\begin{array}{l}\text { Tasa de paro municipal (años inicial y final), y empleos creados } \\
\text { por los PDRs, correlacionados ambos. Distribución territorial } \\
\text { del empleo creado y consolidado. Situación anterior de los tra- } \\
\text { bajadores en relación al empleo, formación y experiencia labo- } \\
\text { ral. Incidencia en la estabilidad laboral. Relevancia de la ayuda } \\
\text { familiar en las empresas apoyadas. Empleo según medidas y } \\
\text { sectores. }\end{array}$ \\
\hline Empresas y empresarios & $\begin{array}{l}\text { Procedencia sectorial, territorial, importancia de las empresas } \\
\text { familiares, condición jurídica, tamaño, volumen de ventas, ám- } \\
\text { bito de venta del producto o servicio, tipo de inversión, motivos } \\
\text { para emprender la actividad y perspectivas de futuro para la de } \\
\text { la zona Leader-Proder. }\end{array}$ \\
\hline Diversificación & $\begin{array}{l}\text { Ocupación por actividades productivas, ocupación anterior de } \\
\text { emprendedores y trabajadores }\end{array}$ \\
\hline Multifuncionalidad & $\begin{array}{l}\text { Edad y sexo de antiguos agricultores, ahora emprendedores, } \\
\text { sector en el que invierte, formación y tamaño empresarial. }\end{array}$ \\
\hline Enfoque integrado & $\begin{array}{l}\text { Grupos que emprendieron acciones de forma coordinada, tipos } \\
\text { de vínculos, temas integradores y dificultades. }\end{array}$ \\
\hline Reparto por medidas & $\begin{array}{l}\text { Inversión (creación, ampliación o modernización), procedencia } \\
\text { territorial del empresario, tamaño empresarial. Su distribución } \\
\text { por medidas en cada territorio de Desarrollo Rural, repercusión } \\
\text { de cada medida y actuaciones principales en cada una de ellas. }\end{array}$ \\
\hline $\begin{array}{l}\text { Tipo (tecnología; productos o servicios; actividades; mercados; } \\
\text { respuestas a problemas). Según sexo, edad, sector, tamaño em- } \\
\text { presarial. } \\
\text { Uso de Internet. } \\
\text { Estudio territorial de la innovación. }\end{array}$ \\
$\begin{array}{l}\text { Estudio de las diferentes actuaciones en cooperación interterri- } \\
\text { torial. }\end{array}$ \\
\hline
\end{tabular}

* Para el análisis poblacional, nos hemos basado principalmente en un estudio similar elaborado por Nieto y Gurria (2005: 479-495).

Elaboración propia.

Por otra parte, debemos indicar que consideramos necesario que las entrevistas en profundidad a los gerentes se basen en las especificidades de LEADER.

Cada uno de los aspectos y de los objetivos de la evaluación plantea una serie de interrogantes que deben tratarse de conocer mediante la utilización de indicadores cualitativos y cuantitativos y que en última instancia deben permitirnos detectar la repercusión del programa en ellos. Presentamos algunos de los más importantes en el cuadro $n^{\circ} 6$ relacionados 
con: las especificidades de los PDRs, prestando un mayor énfasis en sus impactos sobre la variedad y disparidades geográficas de la zona de actuación, los principales problemas demográficos del espacio rural (éxodo rural y envejecimiento), la sociedad, el tejido productivo, y el patrimonio natural y cultural local; sus objetivos (diversificación de actividades, mantenimiento de los efectivos poblacionales, generación de empleo...); la incidencia en determinados colectivos poblacionales, esenciales a la hora de asegurar el reemplazo poblacional (emprendedores, mujeres y jóvenes); y el análisis de cada una de las actuaciones según medidas (formación, turismo, pymes, artesanía, ...), y su plasmación en el tejido productivo local. El estudio de estos componentes, mediante diversas fuentes (informes finales, entrevistas a emprendedores o estadística oficial), métodos (cualitativo-inductivo y cuantitativo-deductivo), y herramientas (hojas de cálculo, bases de datos, sistemas de información geográfica, técnicas estadísticas, ...); de sus cruces e interrelaciones sistémicos, de sus implicaciones socioespaciales, será el pilar básico para desentrañar los verdaderos impactos, en toda su magnitud, en los territorios LEADER-PRODER; de sus logros y errores así como de las enseñanzas extraídas para su aplicación cara al futuro.

\section{CONCLUSIONES}

Los PDRs no han tenido éxito en la consecución de gran parte de sus objetivos, en buena medida por la falta de coherencia entre los problemas a solventar y las medidas planteadas para resolverlos, por la escasez de recursos económicos e incluso por los efectos perversos generados por otras políticas mejor financiadas. Lo anterior no cuestiona que han contribuido sobremanera al cambio de mentalidad de amplios grupos de población rural, que de tener arraigada una mentalidad muy pasiva, acostumbrados al subsidio y sin esperanzas en que pudiera lograrse un verdadero desarrollo de sus pueblos, están pasando poco a poco a creer que sus recursos tanto colectivos como individuales de carácter humano, patrimonial y económico, si son adecuadamente movilizados, pueden impulsar iniciativas que hagan surgir nuevas oportunidades de vida para ellos y sus hijos.

Las circunstancias económicas (carencia de recursos destinados a la evaluación), los problemas derivados por los plazos de la planificación temporal, las múltiples limitaciones burocráticas, las lagunas en las fuentes de seguimiento (de los indicadores del programa, con bases de datos incompletas) y de las estadísticas oficiales (inadecuación, falta de variables, limitaciones temporales, escaso nivel de desagregación espacial y de detalle, problemas de actualización, etc.), la inadecuada metodología existente, la falta de normalización que asegure las comparaciones, y la inexistencia de una cultura de valoración, entre otras cuestiones, impiden que las evaluaciones de PDRs tengan mayores y mejores utilidades. A lo anterior se une el hecho de la elevada complejidad que supone la detección y medición de los efectos de los PDRs. Sus propias especificidades obligan a analizar una gran cantidad de variables a tener presentes un abundante número de factores y elementos que se ven afectados, y frecuentemente diluidos, por la acción de otra serie de actuaciones, entre los que no falta el efecto demostrativo puntual en el tiempo que muchas veces originan estos mismos programas o las grandes transformaciones que acontecen en los espacios rurales y que se deben a circunstancias que sobrepasan los límites locales y se inscriben en la economía global o nacional. 
Se muestra especialmente necesario procurar que las evaluaciones de los PDRs tengan utilidad y que pasen de ser un puro trámite administrativo a convertirse en verdaderos instrumentos de enseñanza que ayuden a la mejora continua de los PDRs. La utilización de fuentes e información de carácter estadístico debe ser necesariamente complementada con otras de carácter cualitativo. Sólo a través ambas se puede construir el armazón necesario para analizar la realidad socioterritorial en general y la rural en particular.

Los organismos encargados de la recogida, tabulación y publicación de información estadística tienen que ser sensibles a las demandas específicas aquí comentadas de normalización, variedad de información desagregada tanto en las dimensiones temática, espacial como temporal. Los expertos y conocedores del mundo académico en estrecha relación con los GAL, deben hacer un esfuerzo de reflexión para sistematizar y normalizar la recogida de información complementaria siempre necesaria y la selección de las más adecuadas variables, elección de indicadores, creación de bases de datos y utilización de técnicas y herramientas, SIGs, más adecuadas para los fines perseguidos. No menos importante, como hemos desarrollado, es conseguir la participación en la evaluación de gestores, técnicos, beneficiarios y del resto de población de la zona Leader-Proder (evaluación participativa), así como la divulgación de los avances que se consigan.

En relación a la metodología cualitativa, quizás la principal aportación que hacemos en este artículo sea la propuesta de cuestionario para realizar una consulta a los emprendedores beneficiados, y para la cuantitativa, propugnamos la utilización de diversos indicadores proporcionados por los propios GAL, que deben ser complementados con otros derivados de la consulta de estadísticas oficiales. De cara al futuro consideramos que se debe profundizar en la obtención de indicadores sintéticos que nos permitan determinar con precisión la dinámica de los impactos de los diversos programas en los territorios y su evolución en el tiempo. La cuestión no es fácil ya que se muestra imprescindible tener en cuenta, entre otras cuestiones, las especificidades de LEADER, las medidas puestas en práctica y las características geográficas de cada uno de los territorios.

Concluyendo, en este artículo defendemos que la evaluación de los PDRs tenga como finalidad determinar, de la manera más precisa posible, el impacto de las actuaciones en el territorio donde se aplica; comprobar en qué medida tales acciones han contribuido a promover el desarrollo de estos territorios de Desarrollo Rural y la reducción de las diferencias de partida respecto a otros territorios. Abogamos por un tipo evaluación que no pierda de vista los objetivos básicos de los programas, que permitan extraer enseñanzas y que fomente el espíritu autocrítico de quienes los diseñan y de quienes los valoran. La necesidad de justificar cada euro que se invierte de fondos públicos y su eficiencia para tratar de conseguir el objetivo de que la igualdad de oportunidades de los ciudadanos no varíe en función del territorio en que viva, nos lo exige y justifica este tipo de estudios.

\section{BIBLIOGRAFÍA CITADA}

AEIDL. (1998): «Innovación en el medio rural». En Evaluar el valor añadido del enfoque LEADER. (Observatorio Europeo LEADER). Bruselas, Cuaderno $\mathrm{n}^{\circ} 4$. Comisión Europea. Disponible en http://www.ec.europa.eu/agriculture/rur/leader2/dossier_p/es/ dossier/chap8.pdf 
AEIDL. (1999): «La competitividad territorial. Construir una estrategia de desarrollo territorial con base en la experiencia de LEADER». (Observatorio Europeo LEADER). Bruselas, Cuaderno $n^{\circ}$ 6, Fascículo 1. Comisión Europea. Disponible en http://www.ec.europa. eu/agriculture/rur/leader2/rural.../biblio.htm

ALARIO, M. y GÜEMES, T. (1998): «Los programas de desarrollo rural integral en Castilla y León» en Perspectivas geográficas sobre el espacio rural. Actas del IX Coloquio de Geografía Rural (Galdos Urrutia, R. y Ruiz Urrestarazu, E., coords.). Bilbao. Universidad del País Vasco y Asociación de Geógrafos Españoles, 11-19.

ALARIO, M. y BARAJA, E. (2006): «Políticas públicas de desarrollo rural en Castilla y León, ¿sostenibilidad consciente o falta de opciones?: Leader II». Boletín de la Asociación de Geógrafos Españoles, no 41, 267-293.

ARKLETON INSTITUTE (2004): The territorial impact of CAP and Rural Development Policy. Aberdeen. ESPON Project 2.1.3, European Spatial Planning Observatory Network. Disponible en http://www.espon.eu

BACHTLER J. \& MICHIE R. (1995): «A new era in EU regional policy evaluation? The appraisal of the Structural Funds». Regional Studies, vol. 29, nº 8, 745-751.

BACHTLER J. \& WREN, C. (2006): «Evaluation of European Union Cohesion Policy: Research Questions and Policy Challenges». Regional Studies, vol. 40.2, 143-153.

BARDAJÍ, I. y GIMÉNEZ, M. (1995): «La iniciativa Leader I y su contribución a la pluriactividad en Castilla y León». Agricultura y Sociedad, $\mathrm{n}^{\circ}$ 77, 147-172.

BARRIO, J.M. et al. (2000): «Innovación y empleo. Estrategias de desarrollo rural para Castilla y León» en Los espacios rurales en el cambio de siglo: incertidumbres ante los procesos de globalización y desarrollo. Actas del X Coloquio de Geografía Rural (García, F.; Larrull, A.; Majoral, R., coords.). Lleida. Asociación de Geógrafos Españoles y Universidad de Lleida, 565-469.

BELTRÁN, C. (1991): «Una iniciativa para el desarrollo rural: LEADER». Revista de Estudios Agrosociales, $\mathrm{n}^{\circ}$ 158, 189-196.

BLAY, J. y ROQUER, S. (2000): «De LEADER II a LEADER +: reflexiones sobre algunas cuestiones clave» en Los espacios rurales en el cambio de siglo: incertidumbres ante los procesos de globalización y desarrollo. Actas del X Coloquio de Geografía Rural de España (García, F.; Larrull, A.; Majoral, R., coords.). Lleida. Asociación de Geógrafos Españoles y Universidad de Lleida. 596-605.

BLAY, J. y ROQUER, S. (2002): «El auge del turismo rural en las zonas de montaña mediterránea de Cataluña en relación con la aplicación de la IC LEADER II» en Los espacios rurales entre el hoy y el mañana. Actas del XI Coloquio de Geografía Rural. Santander. Asociación de Geógrafos Españoles y Universidad de Cantabria. 523-533.

CALATRAVA, J. y GONZÁLEZ, M.C. (2011): «Social ex-post evaluation of local development programs: application of a contingent valuation approach to the Guadix-Marquesado LEADER area (Spain)» en Evidence-based agricultural and rural policy making: methodological and empirical challenges of policy evaluation. Paper prepared for the 122nd EAAE Seminar. Ancona, February 17-18, 2011. Disponible en http://ageconsearch.umn.edu/bitstream/100041/2/calatravarequenagonzalesroa(2).pdf

CAZORLA-MONTERO, A. et al. (2005): «La IC LEADER como modelo de desarrollo rural: aplicación a la región capital de España». Agrociencia, vol. 39, nº 6, 697-708. 
CEJUDO, E. y MAROTO, J.C. (2010): «La reforma de la PAC de 2003: desacoplamiento, condicionalidad, modulación, desarrollo rural». Scripta Nova, Vol. XIV, nº 318, 20 de marzo de 2010. Universidad de Barcelona. Disponible en http:/www.ub.edu/geocrit/sn/ sn-318.htm

CEJUDO, E. y NAVARRO, F. (2009): «La inversión en los programas de desarrollo rural. Su reparto territorial en la provincia de Granada». Anales de Geografía de la Universidad Complutense, vol. 29, $\mathrm{n}^{\mathrm{o}} 2$ 2, 37-64.

CEJUDO, E. y NAVARRO, F. (2003): «El reparto territorial de los Programas de Desarrollo Rural. El caso de la provincia de Granada». Anales de Geografía de la Universidad Complutense, $\mathrm{n}^{\circ} 23,131-162$.

CLIMENT, E. et al. (2000): «La IC LEADER II y el desarrollo rural: el caso de Aragón» en Los espacios rurales en el cambio de siglo: incertidumbres ante los procesos de globalización y desarrollo. Actas del X Coloquio de Geografía Rural (García, F.; Larrull, A.; Majoral, R., coords.). Lleida. Asociación de Geógrafos Españoles y Universidad de Lleida. 111-125.

COMISIÓN EUROPEA (1999a): Ex post evaluation of the LEADER I Community Iniciative 1989-1993. Dirección General de Agricultura. Disponible en http://www.ec.europa.eu/ agriculture/rur/leader1/index_en.htm

COMISIÓN EUROPEA (1999b): Nota de reflexión sobre las modalidades de evaluación expost LEADER II a nivel comunitario. Dirección General de Agricultura. Disponible en http://www.ec.europa.eu/agriculture/rur/leader2/forum/.../note-de-reflexion-ce_es.doc

COMISIÓN EUROPEA (1999c): «Principal evaluation techniques and Tools». In Evaluating socio-economic programmes. Luxemburgo. Means Collection. Comisión Europea. Vol. 3.

COMISIÓN EUROPEA (2005): Evaluación ex post de los programas de desarrollo rural 2000-2006. Dirección General de Agricultura y Desarrollo Rural. Disponible en http:// www.ec.europa.eu/agriculture/rur/eval/expost_es.pdf

COMISIÓN EUROPEA (2006): Synthesis of mid-term evaluations of Leader + programmes. Final Report. Bruselas. Comisión Europea. Disponible en http://www.ec.europa.eu/agriculture/eval/reports/leaderplus/full_text.pdf

CORTÉS, C. (2008): «Resultados de la Iniciativa LEADER II y LEADER + en los municipios rurales de la montaña de Alicante» en Las agriculturas españolas y la Política Agraria Comunitaria: 20 años después. Actas del XIII Coloquio de Geografía Rural. (Araque Jiménez, E. et al., coords.). Baeza. Asociación de Geógrafos Españoles y Universidad Internacional de Andalucía, 421-436.

DELGADO, C. y DE LA FUENTE, M.T. (2000): «Las estrategias de desarrollo rural: una valoración del PRODER en Cantabria» en Los espacios rurales en el cambio de siglo: incertidumbres ante los procesos de globalización y desarrollo. Actas del X Coloquio de Geografía Rural (García, F.; Larrull, A.; Majoral, R., coords.). Lleida. Asociación de Geógrafos Españoles y Universidad de Lleida, 623-634.

DELGADO, M. et al. (1999): «De las nuevas tendencias en evaluación a su aplicación en las iniciativas europeas de desarrollo rural» en El desarrollo rural en la Agenda 2000 (Ramos Real, E., coord.). Madrid. MAPA, 321-344. 
DELGADO, M. et al. (2007): «Nuevas tendencias en evaluación de programas de desarrollo rural territorial: un proceso de autoevaluación en el Altiplano de Granada». Revista Española de Estudios Agrosociales y Pesqueros, $\mathrm{n}^{\circ} 213,11-40$.

DIRECTORATE GENERAL FOR AGRICULTURE AND RURAL DEVELOPMENT (2006): «Handbook on Common Monitoring and Evaluation Framework (CMEF) available». Disponible en http://ec.europa.eu/agriculture/rurdev/eval/indez_en.htm

ESPARCIA, J. (2001): «La evaluación de programas de desarrollo rural» en Lecciones de desarrollo rural. Una aproximación formativa desde y para Castilla-La Mancha (Plaza Tabasco, J. y Pillet Capdepón, F., coords.). Ciudad Real. Universidad de Castilla-La Mancha, 159-166.

ESPARCIA, J. et al. (2000): «LEADER en España: desarrollo rural, poder, legitimación, aprendizaje y nuevas estructuras». Documentos de Análisis Geográficos, n 37, 95-113.

ESPARCIA, J. y NOGUERA, J. (2000): «Aproximación teórico-metodológica a la cultura evaluativa y la evaluación de programas de desarrollo rural». Cuadernos de Geografía de la Universidad de Valencia, $\mathrm{n}^{\circ}$ 67/68, 77-101.

ESTEBAN, M. et al. (2009): «La evaluación de la Política Regional Europea. Análisis empírico de las metodologías aplicadas». Investigaciones Regionales, $\mathrm{n}^{\circ}$ 14, 157-184.

GARCÍA, J-L. et al. (2005): «La iniciativa comunitaria LEADER en España». Boletín de la Asociación de Geógrafos Españoles, n 39, 361-398.

GIL DE ARRIBA, C. (1999): «Programas europeos y desarrollo rural en Cantabria. Actuaciones y perspectivas». Polígonos, $\mathrm{n}^{\circ} 8,39-51$.

GUZMÁN, M. et al. (2001): «Metodología para la evaluación de programas de desarrollo rural». Revista electrónica Infoagro. Disponible en http://www.infoagro.com

HORTELANO, L.A. y MARTÍN, M. I. (1999): «La incidencia de las iniciativas comunitarias y de los fondos europeos en el desarrollo rural de la provincia de Salamanca». Polígonos. $\mathrm{n}^{\circ} 8,53-86$.

JORDÁ, R. (1995): «Metodología de evaluación de la política de desarrollo local» en Cambios regionales a finales del siglo XX. Actas del XIV Congreso Nacional de Geografía. Salamanca. Asociación de Geógrafos Españoles y Universidad de Salamanca, 179-183.

KEARNEY, B. (2002): «Ex post evaluation of Leader II programme in Ireland methods and results summary». Disponible en http://ec.europa.eu/agriculture/rur/Leader2/docs evaluation

LARRULL, A. (1998): «Desarrollo rural y la diversificación productiva: el caso de LEADER I en la Terra Alta (Tarragona)» en Perspectivas geográficas sobre el espacio rural. Actas del IX Coloquio de Geografía Rural (Galdos Urrutia, R. y Ruiz Urrestarazu, E., coords). Bilbao. Asociación de Geógrafos Españoles y Universidad del País Vasco, 113119.

LIMA, M.C. et al. (2010): «Andalucía y el MAC 2000-2006: una evaluación de los fondos estructurales recibidos». Papeles de Economía Española, $\mathrm{n}^{\circ}$ 123, 102-118.

MÁRQUEZ, D. et al. (2005): «Eficacia y eficiencia de LEADER II en Andalucía: aproximación a un índice-resultado en materia de turismo rural». Geographicalia, nº 47, 137-152.

MAYA, A. (1999): «Los Programas de Desarrollo Rural en la provincia de Zamora: ¿iniciativas capaces de dinamizar el atraso socioeconómico de sus espacios rurales?». Polígonos, $\mathrm{n}^{\mathrm{o}} 8,99-128$. 
MORILLAS, A. et al. (1999): «Evaluación de los efectos de los fondos estructurales en la economía andaluza». Estudios Regionales, n $^{\circ}$ 54, 225-249.

MURILLO, E. y SOSVILLA-RIVERO, E. (2005): «Efecto a largo plazo sobre la economía andaluza de las ayudas procedentes de los fondos estructurales: el Marco de Apoyo Comunitario 1994-1999». Investigaciones Regionales, $\mathrm{n}^{\circ}$ 6, 91-124.

NAVARRO, F. (2007): Repercusión de los programas de desarrollo rural en la provincia de Granada. Leader I, II y Proder I. Granada, Universidad de Granada, Tesis Doctoral.

NAVARRO, S. y LARRUBIA, R. (2000): «Los programas LEADER II en la provincia de Málaga. Su contribución al desarrollo del espacio rural». Baética, nº 22, 109-146.

NIETO, A. y GURRÍA, J. L. (2005): «Análisis de la población de los programas de desarrollo rural en Extremadura mediante SIG». Cuadernos Geográficos, nº 36, 479-495.

NOGUERA, J. (2002): «Construyendo un desarrollo integrado, participativo y sostenible: el proyecto LEADER+ en la Isla de Menorca». Cuadernos de Geografía de la Universidad de Valencia, $\mathrm{n}^{\mathrm{o}} 71,91-112$.

NOGUERA, J. y ESPARCIA, J. (2000): «Fundamentos teóricos para un análisis efectivo de las políticas públicas». Cuadernos de Geografía de la Universidad de Valencia, ${ }^{\circ}$ 67-68, 103-118.

OBSERVATORIO EUROPEO LEADER (2001): Guía pedagógica del planteamiento LEADER. Disponible en http://www.ec.europa.eu/agriculture/rur/leader2/.../index.htm

PLAZA, J.I. (2006): «Territorio, geografía rural y políticas públicas. Desarrollo y sustentabilidad en las áreas rurales». Boletín de la Asociación de Geógrafos Españoles, $\mathrm{n}^{\circ} 41$, 69-95.

PÉREZ-FRA, M. M. y VERDUGO-MATES, R. (2005): «Is the LEADER initiative a real contribution to rural development in underdevelopment areas in Europe?». Journal of Social Sciences, $\mathrm{n}^{\mathrm{o}} 1(1), 52-56$.

PILLET, F. y PLAZA, J. (2001): Lecciones de desarrollo rural. Una aproximación formativa desde y para Castilla-La Mancha. Ciudad Real. Universidad de Castilla-La Mancha.

PILLET, F. y SANTOS, J.F. (2008): «Balance de las etapas del desarrollo rural territorial en Castilla-La Mancha: la necesaria política comarcal» en Las agriculturas españolas y la Política Agraria Comunitaria: 20 años después. Actas del XIII Coloquio de Geografía Rural. (Araque Jiménez, E. et al., coords.) Baeza: Universidad Internacional de Andalucía, 605-620.

PLAZA, J.I. (2005): «Desarrollo y diversificación en las zonas rurales de España: el programa PRODER». Boletín de la Asociación de Geógrafos Españoles, no 39, 399-422.

RAY, C. (1998): «Territory, estructures and interpretación. Two case studies of the European Union's LEADER I Programme». Journal of Rural Studies. $\mathrm{n}^{\circ} 14$ (1), 79-87.

RAY,C. (1999): «Towards a meta-framework of endógenos development: Repertoires, paths, democracia and rights». Sociologia Ruralis, $\mathrm{n}^{\circ} 39$ (4), 521-537.

RAY, C. (2000a): «Endogenous socio-economic development in the European union-issues of evaluation». Journal of Rural Studies, $\mathrm{n}^{\circ}$ 16, 447-458.

RAY, C. (2000b): «The EU LEADER Programme: rural development laboratory». Sociologia Ruralis, $\mathrm{n}^{\circ} 40$ (2), 163-171.

RÍOS, I. et al. (2002): «La iniciativa LEADER, un planteamiento de desarrollo rural desde la innovación y el conocimiento local: resultados y experiencias» en Innovación para el 
desarrollo rural. La iniciativa Leader como laboratorio de aprendizaje (Rios, de los, I., coord.). Madrid. Servicio de Documentación y Publicaciones. Comunidad de Madrid, 75-138.

RODRÍGUEZ, A. y FRATESI, U. (2004): «Between development and social policies: the impact of european structructural funds in objective 1 regions». Regional Studies, vol 38.1, 97-113.

RODRÍGUEZ, F. (2001): «Las montañas andaluzas en la encrucijada del desarrollo rural». Eria, n $^{\circ} 54-55,125-139$.

SÁENZ, M. y CEJUDO, E. (2008): «La política de desarrollo rural de la UE para 20072013». Investigaciones Geográficas, $\mathrm{n}^{\circ}$ 46, 5-30.

SÁNCHEZ, M.J. et al. (2000): «Valoración de los programas de desarrollo rural en las áreas periféricas de Castilla y León» en Los espacios rurales en el cambio de siglo: incertidumbres ante los procesos de globalización y desarrollo. Actas del X Coloquio de Geografía Rural (García, F.; Larrull, A.; Majoral, R., coords.). Lleida. Asociación de Geógrafos Españoles y Universidad de Lleida, 714-723.

SÁNCHEZ, M.J. et al. (2008): «La multifuncionalidad en los programas del desarrollo rural en la provincia de León» en Las agriculturas españolas y la Política Agraria Comunitaria: 20 años después. Actas del XIII Coloquio de Geografía Rural. (Araque Jiménez, E. et al., coords.) Baeza. Universidad Internacional de Andalucía, 621-638.

SANTOYO, H. et al. (2002): Manual para la evaluación de programas de desarrollo rural. Madrid. Mundi-Prensa.

SARACENO, E. (1999): «The evaluation of local policy making in Europe. Learning from the Leader Community Initiative». Evaluation, vol. 5, n 4, 439-457.

SARACENO, E. et al. (1999): Evaluar el valor añadido del enfoque LEADER. Cuaderno $\mathrm{n}^{\circ} 4$, Observatorio Europeo LEADER. Disponible en http://www.ec.europa.eu/agriculture/.../leader2/.../contents.htm

SEIBERT, O. (2000): «Análisis de cuellos de botella - un método para la evaluación y valoración de las características cualitativas en el proceso de desarrollo rural» en Mejorar la calidad de las evaluaciones expost de LEADER II. Bruselas. Observatorio Europeo LEADER. Disponible en http://www.ec.europa.eu/agriculture/rur/leader2/forum/docs.../ seibert_es.pdf

SHUCKSMITH, M. (2000): «Endogenous development, social capital and social inclusión: perspectivas from LEADER in the UK». Sociologia Ruralis, no 40 (2), 208-218.

SOSVILLA-RIVERO, S. et al. (2004): «Assessing the effectiveness of EU'S regional policies: a new approach». Centro de Estudios Andaluces. Disponible en http://www.uclm.es/ organos/vic_investigacion/gruposweb/.../pdf/CLMing3.pdf

THIRION, S. (2000): «El método SAP en Portugal (Sistematización de la Autoevaluación Participativa)» en Mejorar la calidad de las evaluaciones expost de LEADER II. Bruselas. Observatorio Europeo LEADER. Disponible en http://www.ec.europa.eu/agriculture/rur/leader2/forum/index-es.htm

TOLEDANO, N. y GESSA, A. (2002): «El turismo rural en la provincia de Huelva. Un análisis de las nuevas iniciativas creadas al amparo de los programas LEADER II y PRODER». Revista de Desarrollo Rural y Cooperativismo Agrario, nº 6, 107-121. 
UNIDAD ESPAÑOLA DEL OBSERVATORIO EUROPEO LEADER (2001): «Aprender de la autoevaluación: algunas recomendaciones básicas tomadas de experiencias de autoevaluación en España». Madrid. Unidad Española del Observatorio Europeo LEADER. Disponible en http://www.redrural.tragsatec.es/redrural/.../Aprender_Autoevaluación.PDF

VÉLEZ, C. (2001): «La evaluación de las políticas públicas en Andalucía: una realidad en proceso de gestación». Cuadernos Económicos de La General de Granada, n 2, 1-14.

VILADOMIU, L. y ROSELL, J. (1998): «Evaluando políticas, programas y actuaciones de desarrollo rural». Economía agraria, nº 182, 297-308.

WARD, N. et al. (2003): «Rural and Regional Development: The Role of the Regional Development Agencies in England». Regional Studies, n 37.2, 201-214. 
